len, wie beispielsweise das plattformspezifische Publikum oder unterschiedliche Plattformlogiken, die für bestimmte Inhalte besser geeignet sind als für andere.

Wie zu erwarten lässt sich weiter resümieren, dass es nur einige wenige Akteur_innen sind, die via Website und Social-Media-Präsenz vergleichsweise hohe Reichweiten erzielen, darunter beispielsweise die Epochtimes, Russia Today Deutsch, Sputnik News, Politically Incorrect, Journalistenwatch oder Junge Freiheit. Diese, wie auch andere besonders reichweitenstarke Seiten, stammen aus Deutschland, was aber nicht bedeutet, dass diese nur von deutschen Leser_innen konsumiert werden. Vielmehr greifen Nutzer_innen aus allen drei Ländern darauf zurück. Infolgedessen ist davon auszugehen, dass es einzelne Gatekeeper im Feld alternativer Nachrichtenmedien gibt, die nicht über viele Rezipierende verfügen, sondern auch im öffentlichen Diskurs eine tragende Rolle einnehmen. Auf diese Frage wird im Zuge der netzwerkanalytischen Untersuchungen (Kapitel VII.3 und Kapitel VII.4) konkreter eingegangen.

Was im Rahmen dieser deskriptiven Analyse nicht beachtet wurde, ist die inhaltliche Ausrichtung oder Art alternativer Nachrichtenmedien. Dieser explorativen Studie liegt - wie bereits thematisiert - die Annahme zugrunde, dass unterschiedliche Ausprägungen oder Typen alternativer Nachrichtenmedien existieren. Schliesslich war für die in diesem Kapitel beschriebenen Newssites das sehr offen gehaltene Kriterium einer «selbstbeschriebenen Alternative zur medialen und/ oder politischen hegemonialen Öffentlichkeit» ausschlaggebend, um in das Sample mitaufgenommen zu werden. Dies impliziert unterschiedliche Ausprägungen. Das nachfolgende Kapitel widmet sich dieser definitorischen Einordnung und Typologie und gleichzeitig der Beantwortung von Forschungsfrage 2.

\title{
VII.2 FF2: Typologie alternativer Nachrichtenmedien
}

Ziel von Forschungsfrage $2^{2}$ ist es, den Begriff «alternative Nachrichtenmedien» genauer zu definieren, zumal die vorliegenden Definitionen im aktuellen Stand der Forschung häufig nicht eindeutig, trennscharf oder zu einschränkend sind (vgl. Kapitel III.4). Weiter basierte die Auswahl des in Forschungsfrage 1 analysierten Samples (bewusst) auf oberflächlichen Kriterien, um das Feld nicht zu stark einzuschränken. Hierbei wurde insbesondere auf die Selbstbeschreibung als Alternative (auch im Sinne einer Ergänzung) oder Opposition zum Establishment aus Politik und Medien und dahingehende Abgrenzung zum professionellen Informationsjournalismus fokussiert. Dieser Ansatz war sinnvoll, um eine Vielzahl unterschiedlicher alternativer Nachrichtenmedien zu erheben. Dieser Pool an 178 erhobenen Websites dient gleichzeitig als Basis für die qualitativen Analysen im Rahmen der in diesem Kapitel be-

2 Vgl. hierzu auch Schwaiger (2021b). 
arbeiteten zweiten Forschungsfrage. Der Forschungslogik der Grounded Theory folgend konnte zu Beginn der Analyse nicht festgelegt werden, wie viele Websites in das qualitative Sample zur Beantwortung dieser Forschungsfrage einfliessen. Die Erhebung wurde nach der Logik des Theoretical Samplings vorgenommen. Startpunkt der Analysen waren besonders resonanzreiche Websites (im Sinne von monatlichen Zugriffen, aber auch gemessen anhand der Social-Media-Community-Grössen, vgl. Kapitel VII.I) aus allen drei Untersuchungsländern. Nach den ersten Auswertungen (vgl. Kodierprozess Kapitel VI.2) wurden weitere, auch kontrastierende Fälle, z. B. Websites mit geringeren Reichweiten, in das Sample mitaufgenommen. Dieser Prozess wurde so lange fortgeführt, bis eine theoretische Sättigung erzielt wurde. Insgesamt wurden 56 Websites aus den drei Ländern qualitativ analysiert (Deutschland: 24; Österreich: 15; Schweiz: 14; DACH-übergreifende Websites: 3; vgl. Anhang 1a), wobei jeweils die Startseiten der Newssites und zudem Subseiten fokussiert wurden, die Aufschluss über das Selbstverständnis der Nachrichtenmedien geben, wie beispielsweise «Über-uns»-Abschnitte. In die Analyse einbezogen wurden ausserdem auf den Seiten publizierte Texte (auf den Homepages vor allem Headliner wie auch die Selbstbeschreibungen) sowie visuelles Material in Form von Bildern oder Logos. Entsprechend wurden auch das Layout und der Aufbau der Websites in die Analyse miteinbezogen - auch aufgrund der Annahme, dass alternative Nachrichtenmedien professionellen Journalismus durch ihre visuelle Gestaltung imitieren wollen, oder in umgekehrter Weise durch das Layout selbst eine Abgrenzung zum etablierten Journalismus vornehmen. Die folgenden Unterkapitel beschreiben die drei Analyseschritte, resultierend in der finalen typologischen Darstellung.

\section{VII.2.1 Offenes Kodieren}

Der erste Analyseschritt des offenen Kodierens verschaffte einen ersten, unvoreingenommenen Blick auf das Datenmaterial. Insgesamt wurden etwa 800 Codes bzw. Konzepte vergeben, die Aspekte der Websites induktiv mit Begriffen oder kurzen Phrasen (vorwiegend selbst festgelegt oder in-vivo, also wortwörtlich aus dem Datenmaterial übernommen) festhielten. So wurden beispielsweise Aspekte des Selbstverständnisses mit Codes wie «politische Unabhängigkeit», «Meinungsfreiheit» oder «fundierter Journalismus» versehen. Oder aber es wurden konkrete Thematiken wie «Kritik an Merkel», «Gewalt von Migranten», «Angst vor Terror» etc. wie auch Aspekte des Layouts (z. B. «düsterer Farbcode», «Verlinkung von Videos» etc.) kodiert. Parallel wurden Memos erstellt, die unterstützend für die Theoriebildung herangezogen wurden, wie beispielsweise etwaige Auffälligkeiten in Daten, mögliche Zusammenhänge oder Unterschiede zwischen einzelnen Codes. Besonders bei Uneinigkeiten im Datenmaterial, wie etwaigen Widersprüchen, wurden jeweils weitere Daten (respektive Websites) in die Analyse mitein- 
bezogen - dies über den ganzen Forschungsprozess hinweg. ${ }^{3}$ Somit waren Datenerhebung, Kodieren und das Schreiben von Memos von einem zirkulären Prozess geprägt, was wesentlich für die angestrebte Theoriebildung ist. Darüber hinaus wurden im Rahmen des offenen Kodierens bereits erste Kategorien und Subkategorien im Sinne einer hierarchischen Anordnung der Codes festgehalten, um erste sich abzeichnende Bezüge herzustellen. Die Kategorien wurden dabei - wie von Glaser und Strauss (1967) empfohlen - «dimensionalisiert». So kann beispielsweise die Kategorie «Politikkritik» (die wiederum aus mehreren Subkategorien besteht) mehrdimensional betrachtet werden, z. B. anhand des politischen Spektrums: In Abhängigkeit vom untersuchten Medium (oder Medientyp) kann sich Kritik am politischen Establishment in unterschiedlicher Weise äussern. Dies beispielsweise insofern, als entweder «linke», «grüne» oder «rechtspopulistische» Politik und deren Amtsträger_innen abgelehnt werden, oder aber schlicht das «Establishment» an sich. Ebenso lässt sich beispielhaft die Kritik an klassischen Leitmedien mehrdimensional einordnen: Die Kritik kann sich in ihrer Extremform dahingehend äussern, dass die «Mainstreampresse» mit lügenhaften Darstellungen dieser konnotiert wird (Stichwort: «Lügenpresse»), oder aber es wird - am anderen Ende des Spektrums - die durch den Strukturwandel hervorgebrachte Kommerzialisierung des Mediensystems abgelehnt, die mit Ressourceneinbussen und zu geringer Rechercheleistung einhergeht. Ferner zeigt sich im Datenmaterial auch eine Bandbreite respektive Mehrdimensionalität bezugnehmend auf die Finanzierung der einzelnen Medien: Bereits im offenen Kodierprozess wurde deutlich, dass nicht alle Medien nichtkommerziell agieren (wie es Definitionen der Alternativpresse der 1960er- und 1970er-Jahre nahelegen), sondern etwa über Spendenaufrufe bis hin zu kostenpflichtigen Abonnements für finanzielle Ressourcen sorgen. Diese Kategorien der Kritik am politischen Establishment, Kritik des klassischen Journalismus und Finanzierung sollen an dieser Stelle nur exemplarisch aufzeigen, dass alternative Nachrichtenmedien in unterschiedlichen Erscheinungsformen auftreten. Damit wird die bereits aus dem Forschungsstand abgeleitete Annahme unterschiedlicher Typen alternativer Nachrichtenmedien im deutschsprachigen Raum bestätigt:

These 1 (FF2): Alternative Nachrichtenmedien müssen divers betrachtet werden: Im deutschsprachigen Raum gibt es unterschiedliche «Typen» alternativer Nachrichtenmedien.

Diese These wurde schliesslich im nächsten Analyseschritt, dem axiale Kodieren, weiter verfolgt.

3 Für die Argumentationslinie und den besseren Lesefluss wird im Weiteren nicht mehr darauf hingewiesen, an welcher Stelle weitere Daten erhoben wurden. 


\section{VII.2.2 Axiales Kodieren}

Das axiale Kodieren verfolgt das Ziel, Beziehungen und Muster zwischen den bereits identifizierten Kategorien aufzudecken, um schliesslich potentielle Schlüsselkategorien - das Herzstück der zu erarbeitenden Theorie - in Erfahrung zu bringen. Hierzu wurden vorläufige Hauptkategorien näher analysiert, woraufhin zudem das Datenmaterial neu kodiert wurde, um Bedingungen, den Kontext, Strategien und Konsequenzen hinter einzelnen Phänomenen (in diesem Fall den entwickelten Hauptkategorien) zu identifizieren - wie es auch das Kodierparadigma von Strauss und Corbin (1990, S. 96-115) verlangt. Konkret wurde nach diesem Prozedere für folgende Kategorien vorgegangen, zumal alle weiteren erstellten Codes unter diese Hauptkategorien subsumiert werden können ${ }^{4}$ :

- Kritik am «Mainstream» (professioneller Journalismus)

- Kritik am politischen Establishment

- Selbst- und Journalismusverständnis

- Themenfokus

- Finanzierung

- Akteur_innen(Autor_innen und Publikum)

- Layout und Rhetorik

Die folgenden Darstellungen sollen anhand des Kodierparadigmas die Beziehung zwischen einzelnen Subkategorien und den einzelnen Phänomenen des Analysematerials aufzeigen. ${ }^{5,6,7}$ Zentral ist in den Abbildungen jeweils die entsprechende Hauptkategorie abgebildet, umrandet von den Kodiereckpfeilern nach Strauss und Corbin (1990): Darunter die Ursächlichen Bedingungen, Intervenierenden Bedingungen, der Kontext sowie die Strategien und Konsequenzen, unter die die jeweiligen Subkategorien (die häufig selbst noch weitere Sub-Subkategorien implizieren) zur Erklärung des Phänomens zusammengefasst werden. Die fünf Kodieraspekte können dabei als «Fragen» an das Datenmaterial betrachtet werden.

4 Die angegebene Reihenfolge ist nicht mit einer Rangfolge i. S. einer unterschiedlichen Cewichtung zu deuten.

5 Aus Platzgründen wird auf eine graphische Darstellung aller sieben Hauptkategorien verzichtet; stattdessen werden nur folgende Kategorien beispielhaft dargestellt: «Kritik am «Mainstream» (professioneller Journalismus)», «Selbst- und Journalismusverständnis» sowie «Layout und Rhetorik». Alle weiteren Kategorien werden schriftlich ausgeführt.

6 Alle Kategorien beziehen sich auf den subjektiven Sinn der analysierten Nachrichtenmedien und entsprechen keiner normativen Bewertung.

7 Empirische Beispiele zu den Kategorien werden hier ausgespart und erst bei der finalen Ergebnispräsentation der Typologie veranschaulicht. 
Die erste Hauptkategorie (bzw. das erste Phänomen), auf die/das im Folgenden näher eingegangen wird, wurde als «Kritik am Mainstream» bezeichnet (vgl. Abbildung 2). «Mainstream» bezieht sich hierbei auf den klassischen Informationsjournalismus und soll an dieser Stelle nicht (nur) negativ wertend gedeutet werden. Vielmehr ist der Fokus dieses Phänomens die von alternativen Nachrichtenmedien subjektiv latent oder manifest geäusserte Kritik am klassischen Journalismus, von dem sich schliesslich abzugrenzen versucht wird. Die ursächlichen Bedingungen geben an, was zu diesem Phänomen führt. Hierunter lassen sich die Subkategorien «Unzufriedenheit mit dem klassischen Journalismus» und «Abgrenzung vom klassischen Journalismus» fassen: Die Unzufriedenheit kann sich wieder in unterschiedlichen Dimensionen äussern: z. B. hinsichtlich mangelnder Rechercheleistung klassischer Medien oder der Annahme, dass absichtlich Lügen (oder «Fake News») verbreitet werden. Die Abgrenzung vom klassischen Journalismus als Ursache für die Kritik ergibt sich daraus, dass die untersuchten Medien ihr Alleinstellungsmerkmal klar kommunizieren wollen; sie positionieren sich als Alternative aufgrund der Unzufriedenheit mit dem «Mainstream», was eine Bedingung für die daraus resultierende Kritik darstellt. Die intervenierenden Bedingungen beschreiben die sogenannten Vorbedingungen für die Strategien, bezogen beispielswiese auf zeitliche, räumliche, kulturelle oder biographische Dimensionen (Strauss \& Corbin, 1990, S. 103). Darunter fällt für das Phänomen «Mainstreamkritik» die Sub-Kategorie «Wandel des Mediensystems» als aktive Bezugnahme der Nachrichtenmedien auf den Medienwandel, der sich beispielsweise in Form von Veränderungen der Presselandschaft durch die Digitalisierung und den damit einhergehenden finanziellen Druck klassischer Medien manifestiert (was teilweise durchaus positiv von den analysierten Medien herausgestrichen wird). Ebenso relevant sind an diesem Punkt die zu Wort kommenden Akteur_innen, die schliesslich Kritik äussern - d. h. die Journalist_innen oder auch Laienjournalist_innen. Wie die Kritik geäussert wird, hängt folglich davon ab, von welchem/welcher Akteur_in diese getätigt wird, sowohl inhaltlich als auch rhetorisch ${ }^{8}$. Dies hängt schliesslich damit zusammen, was genau am journalistischen «Mainstream» kritisiert wird, wie auch am Kontext und den Strategien deutlich wird. Der Kontext des Phänomens beschreibt gleichzeitig die Bedingungen für die darauffolgenden Strategien. Unter «Kontext» wurden die Kategorien «Unterschiedliches Journalismusverständnis» und «Unterschiedliches Selbstverständnis» subsumiert. Massgeblich für die Strategien alternativer Nachrichtenmedien bzw. deren Akteur_innen ist demnach, wie sich die Medien im Hinblick auf ihre «Mission», also auf ihre Ziele und Motive (z. B. «Aufdeckung falscher Berichterstattung» oder «gesellschaftliche Verantwortung»), sowie bezüglich ihres Verständnisses, wie Journalismus praktiziert werden soll (z. B. «politische Unabhängigkeit», «fun-

8 Aufdie unterschiedlichen zu Wort kommenden Akteur_innen wird an spätererStelle, im Rahmen der finalen Typologiebildung, detailliert eingegangen (vgl. Kapitel VII.2.3) 
dierter Journalismus», «Meinungsfreiheit» etc.), selbst definieren. Die Strategien beschreiben die Handlungen oder Interaktionen hinter dem Phänomen. Ein Blick auf die in Abbildung 2 dargestellten Strategien - bzw. die darin subsumierten Kategorien/Codes - verdeutlicht, dass die Mainstreamkritik in unterschiedlicher Form auftreten kann, was wiederum die These bestätigt, dass unterschiedliche Typen alternativer Nachrichtenmedien existieren. Die Strategien können wieder anhand eines Spektrums dargestellt werden: Von einer eindeutigen negativen Bewertung respektive sogar Aberkennung des Wahrheitsanspruches klassischer Informationsmedien im Sinne eines «Fake News»-, «Lügenpresse»- oder Manipulationsvorwurfs, über den Versuch, Verschwörungen innerhalb des medialen «Mainstreams» aufzudecken, bis hin zu einer Ablehnung potentieller politischer Einflussnahme bei der Berichterstattung, der Kommerzialisierung des Mediensystems oder einer $\mathrm{zu}$ einseitigen Berichterstattung, die $\mathrm{zu}$ wenig Rechercheleistung beinhaltet. Die Äusserung ebendieser Kritikpunkte kann in unterschiedlichen Ausprägungen auftreten und von einem aggressiven, zynischen Ton, über den Versuch, klassische Informationsmedien ins Lächerliche zu ziehen, bis hin zu einer neutralen, sachlichen Kritik reichen. Eng verbunden mit den Strategien sind die Konsequenzen, also die Resultate der jeweiligen Strategien. Diese zeigen sich im Datenmaterial deutlich in Form eines Aufrufes an die Leser_innen. Dahingehend ist beispielhaft der Aufruf $\mathrm{zu}$ nennen, den klassischen Informationsjournalismus kritischer zu hinterfragen oder gar zu vermeiden; oder aber der Aufruf, alternative Nachrichtenmedien zu unterstützen, sei es in Form von journalistischer Unterstützung von Lai_innen oder auch finanzieller Art in Form von Spenden etc.

Abbildung 2: Kodierparadigma für die Hauptkategorie «Kritik am «Mainstream (professioneller Journalismus)» (Eigene Darstellung)

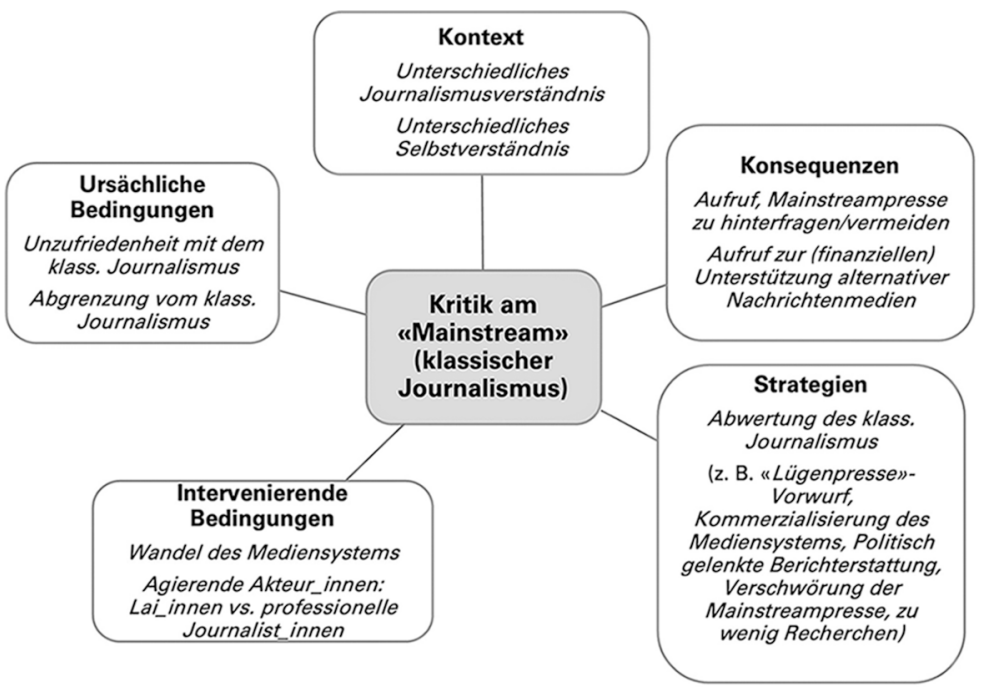


Sehr ähnlich kann auch die Hauptkategorie «Kritik am politischen Establishment» anhand des Kodierparadigmas betrachtet werden, zumal es zwischen den beiden Kategorien «Mainstreamkritik» und «Politikkritik» zahlreiche Überschneidungen gibt. An diesem Punkt der Analyse wird erneut deutlich, dass die Kritik-und Kontrollfunktion ein wesentliches Definitionskriterium alternativer Nachrichtenmedien darstellt, wenn auch in unterschiedlicher Ausprägung, je nach Medientyp.

These 2 (FF2): Ein wesentliches (subjektives) Definitionskriterium alternativer Nachrichtenmedien ist die Kritik- und Kontrollfunktion gegenüber der hegemonialen Öffentlichkeit aus Medien und Politik.

Die ursächlichen Bedingungen des Phänomens «Kritik am politischen Establishment» lassen sich (ähnlich der «Mainstream-Medienkritik») durch die Kategorie «Unzufriedenheit» fassen. Die Unzufriedenheit gegenüber politischen Eliten äussert sich wiederholt in unterschiedlicher Form, beispielsweise gegenüber bestimmten politischen Parteien aus verschiedenen politischen Lagern, den «Eliten» generell oder deren Repräsentativität der Bürger_innen. Intervenierende Bedingungen werden vor allem durch den Rückbezug der Medien auf gesellschaftliche Krisen oder Umbrüche offensichtlich, wie beispielsweise die so bezeichnete «Flüchtlingskrise» $\mathrm{ab} 2015$ oder auch das politische System sowie unterschiedliche politische Amsträger_innen, gegen die sich die Kritik richten kann. Der Kontext stimmt mit jenem der Kritik am professionellen Informationsjournalismus überein und stützt sich auf das jeweilige Journalismus- bzw. Selbstverständnis, das massgeblich dafür ist, wie sich die Kritik am politischen Establishment konkret mit ihren jeweiligen Strategien äussert. Die Strategien ähneln jenen der «Mainstream-Medienkritik» insofern, als auch diese darauf beruhen, wie das Thema - in diesem Fall «Politik» oder "politische Eliten» - in den Medien selbst reflektiert wird. Darunter finden sich beispielsweise die abwertende Berichterstattung gegenüber bestimmten politischen Parteien oder deren Repräsentant_innen (darunter z. B. ganz stark die ablehnende Haltung gegenüber Angela Merkel oder auch die Ablehnung von rechts- oder linkspopulistischen Parteien oder Grossparteien generell) sowie der konkrete Vorwurf, Bürger_innen würden nicht angemessen repräsentiert. Dementsprechend zeigt sich die Kritik (und auch Kontrolle im Sinne einer Vierten Gewalt) in Abhängigkeit vom Medientyp in ganz unterschiedlichen Dimensionen. Dies spiegelt sich darin wider, wie politische Medienbeiträge gerahmt werden; teils implizit (z. B. durch das sachliche Aufzeigen aktueller gesellschaftlicher Probleme) oder explizit (z. B. durch Vorwürfe, es würden Lügen von politischen Eliten verbreitet, Zensurvorwürfe oder den Vorwurf der Unfähigkeit von Politiker_innen) gegen bestimmte politische Lager oder auch das politische System selbst. Auch die Konsequenzen ähneln jenen der vorrangig besprochenen Kritik gegenüber den «Mainstreammedien»: Der Aufruf zum 
aktiven Handeln der Leser_innen steht klar im Vordergrund, z. B. in Form von Demonstrationen, bis hin zu einer Revolution oder der Auswanderung (aufgrund schlechter Zustände im Heimatland), wie auch der Forderung nach sozialer Gerechtigkeit oder der warnenden Prophezeiung des Untergangs des Landes (z. B. Deutschland).

Eine weitere Kategorie, die bereits zur Erklärung des Kontextes der ersten beiden Phänomene («Mainstream-Medienkritik» und «Politikkritik») herangezogen wurde, allerdings tragend für die Beantwortung der Frage nach der Definition alternativer Nachrichtenmedien erscheint, ist das «Selbst- und Journalismusverständnis» ${ }^{9}$. Aus diesem Grund wird diese als identifizierte Hauptkategorie näher analysiert und mit anderen Kategorien in Beziehung gesetzt (vgl. Abbildung 3).

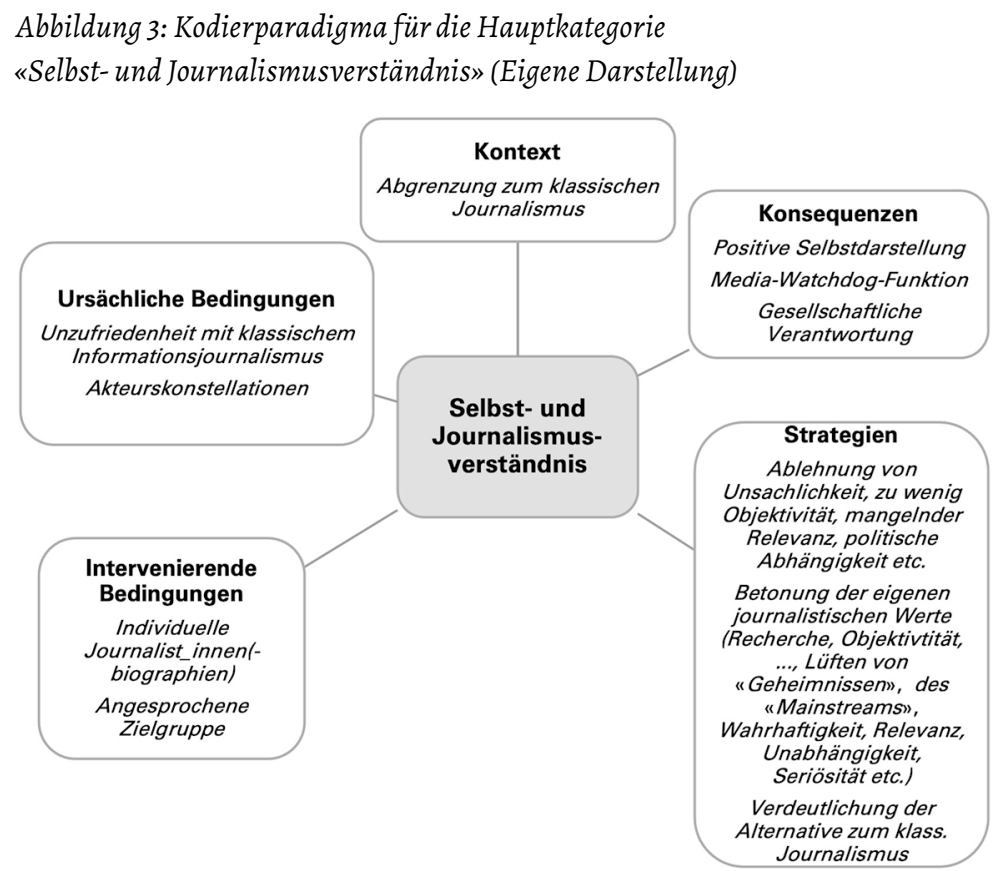

Das «Phänomen» Selbst- und Journalismusverständnis wird ursächlich durch unterschiedliche Faktoren bedingt: Einerseits durch die Unzufriedenheit mit dem klassischen Informationsjournalismus, die erst dazu führt, dass das Selbst- bzw. Journalismusverständnis in einer bestimmten Form ausgeprägt ist und sich «neue» alternative Nachrichtenmedien zu etablieren versuchen. Diese Unzufriedenheit

9 Aufgrund inhaltlicher Überschneidungen zwischen Selbst- und Journalismusverständnis wurden die beiden Kategorien in eine Hauptkategorie zusammengefasst. 
konnte bereits bei weiteren beschriebenen Hauptkategorien respektive Phänomenen als wesentliches Kriterium identifiziert werden und scheint demnach ein wesentliches Definitionskriterium alternativer Nachrichtenmedien zu sein. Ebenfalls relevant für die Ausbildung des Selbst- und Journalismusverständnisses sind die jeweiligen Akteurskonstellationen, die hinter den Nachrichtenmedien stehen. Unter Akteurskonstellationen ist zu verstehen, wer die Nachrichtenbeiträge produziert und verbreitet. In Abhängigkeit davon, ob es sich um professionelle Journalist_innen handelt oder Laienakteur_innen, die Beiträge erstellen, kann sich das Selbst-/Journalismusverständnis stark unterscheiden. So werden journalistische Qualitätskriterien wie z. B. Relevanz, Objektivität und Unabhängigkeit vor allem von Journalist_innen etwa in einer professionellen Redaktion des Nachrichtenmediums eingehalten, während Laienjournalist_innen unter Umständen andere - selbst auferlegte - journalistische Werte und Selbstbilder publizieren. Ein solches Selbstbild kann beispielsweise Meinungsfreiheit dahingehend sein, auch Beiträge zuzulassen, die nicht einer «political correctness» entsprechen. Die konkreten Ausprägungen des Selbst- und Journalismusverständnisses werden in Kapitel VII.2.3 im Rahmen der Ergebnispräsentation detailliert dargestellt. Die Rolle der Journalist_innen wie auch deren (Berufs-)Biographien stellen auch eine wesentliche intervenierende Bedingung dar. So können beispielsweise Näheverhältnisse zu politischen Parteien eine wesentliche Rolle dahingehend spielen, wie das Selbstbild der Nachrichtenmedien ausgestaltet ist. Auf Akteursebene ist zudem das angesprochene Publikum relevant, also die Zielgruppe des Nachrichtenmediums. Dieses wird teilweise von den Nachrichtenmedien aktiv angesprochen (z. B. durch die Ausrichtung an besonders kritische Leser_innen; Leser_innen, die Hintergrundberichterstattung zu relevanten Themen verlangen; Leser_innen, die den Lügen des «Mainstreams» misstrauen). Das (journalistische) Selbstbild sollte folglich den Bedürfnissen der Zielgruppe entsprechen. Wesentlich für die Strategien ist wiederum der Kontext des Phänomens. Als Kontextbedingung für das Selbst- und Journalismusverständnis wird im Fall alternativer Nachrichtenmedien die nötige Abgrenzung dieser gegenüber klassischen, etablierten Informationsmedien gedeutet. Demzufolge ist ein wesentliches Kriterium der Selbstdefinition, eine wörtliche «Alternative» zum klassischen Informationsjournalismus einzunehmen. Immer dann, wenn diese Abgrenzung deutlich gemacht werden muss, kommen spezifische Strategien zur Anwendung. Zu diesen Strategien zählt u. a. die Verdeutlichung der Andersartigkeit durch eine Ablehnung klassischer Nachrichtenmedien mangels Nichteinhaltung spezifischer journalistischer Werte. So wird beispielsweise eine Abgrenzung dadurch geschaffen, dass klassischen Informationsmedien Unsachlichkeit, mangelnde Objektivität und Relevanz oder politische Abhängigkeit vorgeworfen wird. Oder es werden eigene Werte hervorgehoben, wie die bereits erwähnte Meinungsfreiheit, tiefgehende Rechercheleistungen, politische Unabhängigkeit bis hin zur Aufdeckung vermeintlicher Lügen 
des medialen Establishments. Die aus den Strategien abgeleiteten Konsequenzen umfassen die positive Selbstdarstellung der alternativen Nachrichtenmedien (z. B. insofern, als fundierter Journalismus geboten werde) und die einnehmende Funktion als Media-Watchdogs im Sinne einer Vierten Gewalt, die Politik und Medien kontrolliert bzw. kritisiert und dahingehend gesellschaftliche Verantwortung übernimmt. Folgende These kann aus der Analyse abgeleitet werden:

These 3 (FF2): Alternative Nachrichtenmedien unterscheiden sich anhand ihres Selbst-und Journalismusverständnisses voneinander.

Als weitere tragende Hauptkategorie wurde der Themenfokus genauer analysiert und mit weiteren Kategorien in Beziehung gesetzt. Der Themenfokus, also über welche Themen die Nachrichtenmedien berichten, orientiert sich stark an der Einstellung gegenüber dem politischen wie auch medialen Establishment (ursächliche Bedingungen) und wird durch aktuelle gesellschaftliche Ereignisse (intervenierende Bedingungen) beeinflusst. Interessanterweise scheinen länderspezifische Themen eine geringere Rolle zu spielen; so werden vor allem Themen mit Deutschlandoder generell internationalem Bezug auch von den österreichischen und Schweizer Medien aufgegriffen. Auch bei dieser Hauptkategorie zeigten sich deutliche Unterschiede in den jeweiligen Kategorienausprägungen, weshalb wiederum davon auszugehen ist, dass es unterschiedliche Typen alternativer Nachrichtenmedien gibt. Beispielsweise können vor allem politische Sympathien oder Antipathien wie auch das Selbstverständnis der Nachrichtenmedien (Kontext) den Themenfokus und die entsprechende Berichterstattung beeinflussen. Die Strategien beruhen vor allem darauf, wie die Themen verhandelt werden - also beispielsweise, ob es sich um eine sachliche, objektive oder auch (z. B. politisch) wertende oder kritische Darstellung bestimmter Themen handelt. Als ebenso divers sind die Konsequenzen zu beschreiben, die von einer neutralen Wissensvermittlung bis hin zu einer Wertung hinsichtlich der behandelten Themen reichen. Weiter stellte sich im Zuge der Analyse heraus, dass die Rahmung der Themen für die Erklärung des Phänomens «alternative Nachrichtenmedien» interessanter ist als die Themenwahl selbst, da hier stärkere Kontraste identifiziert werden konnten. Eine konkrete Analyse des Themenfokus kann schliesslich erst dann erfolgen, wenn eine differenzierte Betrachtung nach «Medientyp» erfolgt:

These 4 (FF2): Alternative Nachrichtenmedien unterscheiden sich in ihrer thematischen Ausrichtung voneinander.

These 5 (FF2): Alternative Nachrichtenmedien agieren stark länderübergreifend: Sie bedienen Themen aus dem gesamten deutschsprachigen Raum und sprechen gleichbedeutend ein Publikum aus dem gesamten DACH-Raum an. 
Ebenso wurde die Hauptkategorie Finanzierung tiefgehender analysiert. Diese bezeichnet deshalb ein interessantes Phänomen, da kommerzielle Aktivitäten im Kontext von Alternativmedien im aktuellen Forschungsstand meist ausgeklammert werden. Vielmehr besteht die Annahme, dass sich die Alternative auch dadurch ergibt, dass nicht gewinnorientiert agiert wird. Dies konnte im Zuge der Analyse des empirischen Materials allerdings nicht bestätigt werden. Denn, wie nun mehrfach beschrieben wurde, variieren die Finanzierung bzw. ökonomischen Aktivitäten generell stark zwischen den analysierten Nachrichtenmedien. Als ursächliche Bedingung können entsprechend der Medientyp oder auch bestimmte (z. B. kommerzielle oder politische) Ziele, die hinter der Verbreitung der Nachrichtenmedien stehen, angenommen werden, was sich allerdings anhand dieser Daten nicht empirisch belegen lässt. Intervenierend bedingt wird die Finanzierung durch die agierenden Akteur_innen, also die jeweiligen Journalist_innen respektive Laienjournalist_innen und deren berufliche Biographien (z. B.: handelt es sich um die hauptberufliche Tätigkeit oder ein Hobby etc.). Ebenso wird die Finanzierung durch den medialen Wandel beeinflusst, der es zulässt, ohne grosse Barrieren und kostengünstig (Nachrichten-)Websites zu lancieren, was wiederum simple Möglichkeiten hervorbringt, z. B. Gelder über Crowdfunding zu gewinnen. Kontextuell bedingt werden die Strategien durch das Selbstverständnis der Medien hinsichtlich der Ziele und Motive. Zu den Strategien zählen schliesslich der aktive Aufruf zur finanziellen Unterstützung, beispielsweise durch Spenden, das Angebot kostenpflichtiger Abonnements, oder die Einbettung von Werbungen in die Website. Das Spektrum ist dabei breit und variiert zwischen den einzelnen Nachrichtenmedien; so wird beispielsweise in manchen Fällen die Finanzierung über Werbung aktiv abgelehnt. Dennoch ähneln sich die Konsequenzen dahingehend, dass - zumindest in irgendeiner Form - das (finanzielle) Überleben des Onlinemediums angestrebt wird. Daraus wird folgende These abgeleitet:

These 6 (FF2): Alternative Nachrichtenmedien unterscheiden sich in ihren ökonomischen Strukturen voneinander.

In der Hauptkategorie «Akteur_innen» werden sowohl die von Medienseite agierenden Akteur_innen, wie Journalist_innen, Redakteur_innen, oder auch Organisationen (z. B. Non-Profit-Organisationen), betrachtet, als auch jene Personen, die von dem Medium angesprochen werden sollen (zumindest aus Sicht der Nachrichtenmedien). Beide Akteursgruppen werden ursächlich davon beeinflusst, welche thematische Ausrichtung das Nachrichtenmedium und ggf. welche Historie das Medium hat. Intervenierend bedingt wird das Phänomen durch die individuellen Biographien der Akteur_innen (z. B. der Journalist_innen). Kontextuell evoziert wird das Phänomen wiederum durch das Selbst- und Journalismusverständis der Nachrichtenmedien. $\mathrm{Zu}$ den Strategien zählen einerseits die Selbstbeschreibun- 
gen der zu Wort kommenden Akteur_innen (z. B. durch Kenntlichmachen eines «Expert_innenstatus» aufgrund von Ausbildungen oder dem beruflichen Werdegang) sowie die gezielte Ansprache bestimmter Publika (z. B. «kritische Leser_innen», «Bürgerorientierung» etc.) - dies auch durch die Einbindung der Leser_innen (der «Community») über Kommentarfunktionen. Unter Konsequenzen fallen schliesslich eine spezifische Publikumsorientierung und positive Selbstdarstellung des Nachrichtenmediums durch die agierenden Akteur_innen. Die folgende These wird im weiteren Analyseprozess weiterverfolgt:

These 7 (FF2): Alternative Nachrichtenmedien werden von unterschiedlichen Akteur_innen betrieben und sprechen ein unterschiedliches Publikum an.

Als letzte Hauptkategorie wurde im Rahmen des axialen Kodierprozesses «Layout und Rhetorik» behandelt (vgl. Abbildung 4). Darunter sind die visuelle Darstellung der Nachrichtenmedien wie auch der Sprachstil in der Berichterstattung zu verstehen. Auch hinsichtlich dieses Phänomens konnten grosse Unterschiede zwischen den einzelnen analysierten Nachrichtenseiten festgestellt werden, weshalb als Kontext der Medientyp festgehalten wird, unter der Annahme, dass es auch unter alternativen Nachrichtenmedien unterschiedliche Medientypen gibt. Ursächlich bedingt wird die Hauptkategorie einerseits durch die finanziellen Mittel, also die Finanzierung des Mediums, die, wie bereits ausgeführt, stark zwischen den Nachrichtenmedien variiert und insbesondere die Möglichkeiten der visuellen Darstellung beeinflusst (im Sinne einer Professionalisierung des Layouts). Andererseits wird sie durch die «Organisationsform» des Mediums beeinflusst, die wiederum in unterschiedlichen Dimensionen betrachtet werden kann (z. B. Non-Profit, professionelle Redaktion, Kollaboration von Bürger_innen respektive Lai_innen etc.). Diesbezüglich ist anzunehmen, dass sich eine Professionalität in der Organisationsform auch in einer entsprechenden Professionalität des Layouts und der Rhetorik/des Schreibstils widerspiegelt. Intervenierend bedingt werden Layout und Rhetorik erstens durch die Zielgruppe, die angesprochen werden soll, und zweitens durch die individuellen Autor_innen der Beiträge mit unterschiedlichen Berufsbiographien und journalistischen Erfahrungswerten. Zu den Strategien zählen hinsichtlich des Layouts der Einsatz von Symboliken in der visuellen Darstellung wie auch spezifische farbliche Darstellungen (z. B. düster oder schlicht gehalten). Teilweise liessen sich im analysierten Material auch grosse Ähnlichkeiten in der visuellen Gestaltung zu etablierten, klassischen Nachrichtenmedien feststellen, und es erfolgte häufig eine Einbettung von audiovisuellem Material und Verlinkungen zu weiteren Nachrichtenseiten oder YouTube-Kanälen. Der Schreibstil variiert stark zwischen den Medientypen, da eine grosse Varianz hinsichtlich der Autor_innen der Texte besteht. Die aus den Strategien folgende Konsequenz ist die Verdeutlichung des Selbstbildes oder Selbstverständ- 
nisses der Medien, das durch Optik und Sprache des Mediums widergespiegelt wird. Daraus resultieren folgende Thesen:

These 8 (FF2): Alternative Nachrichtenmedien unterscheiden sich in ihrer visuellen Darstellung voneinander.

These 9 (FF2): Alternative Nachrichtenmedien unterscheiden sich in ihrer Rhetorik voneinander.

These 10 (FF2): Alternative Nachrichtenmedien sind untereinander vernetzt: Sie verlinken sich gegenseitig und referenzieren aufeinander.

Abbildung 4: Kodierparadigma für die Hauptkategorie "Layout und Rhetorik» (Eigene Darstellung)

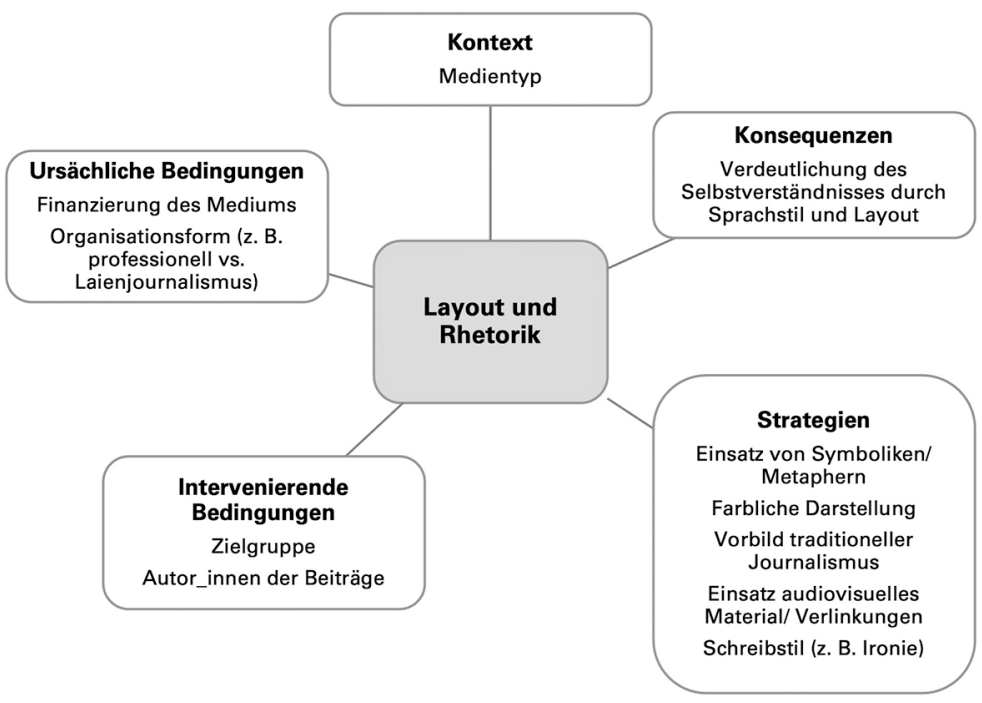

Die detaillierte Betrachtung der Hauptkategorien durch Einbettung in das Kodierparadigma verdeutlichte die Verzahnung zwischen einzelnen Kategorien und erwies sich als wesentlich für weitere Analyseschritte. Die Analyse im Zuge des axialen Kodierens resultierte in der Formulierung von Thesen, die für die Theorieentwicklung von grosser Bedeutung sind. Die Ergebnispräsentation erfolgt im sich anschliessenden Kapitel. 


\section{VII.2.3 Selektives Kodieren und Theoriebildung}

Nachdem in der intensiven Auseinandersetzung mit dem Datenmaterial im Zuge des axialen Kodierens wesentliche Kategorien und deren Verbindungen untereinander identifiziert wurden, dient der letzte Schritt des selektiven Kodierens der Herausarbeitung der Schlüsselkategorie(n), um eine theoretische Weiterentwicklung vornehmen zu können. Massgeblich für die Theoriebildung (respektive Neudefinition alternativer Online-Nachrichtenmedien im deutschsprachigen Raum) waren die gebildeten Thesen - darunter besonders zentral die in den vorhergehenden Analyseschritten bestätigte Annahme, dass unterschiedliche Typen alternativer Nachrichtenmedien existieren, die sich anhand bestimmter Kriterien (oder: Kategorien) voneinander unterscheiden. Die wesentliche Schlüsselkategorie auf der Suche nach dem zentralen Definitionskriterium wurde als «Alternative Nachrichtenmedien als Vierte Gewalt» definiert. Die Kritik- und Kontrollfunktion alternativer Nachrichtenmedien gegenüber der Politik und den klassischen Informationsmedien (also dem politischen und medialen Establishment, vgl. Analyseschritt des axialen Kodierens, Kapitel VII.2.2) erwies sich bereits in den vorangegangenen Analyseschritten als zentral, sowohl in den Selbstbeschreibungen als auch in der Themenwahl der analysierten Medien. Die Opposition alternativer Nachrichtenmedien gegenüber dem so bezeichneten «Mainstream» drückt sich demnach aktiv in der kritisierenden und kontrollierenden Korrektivfunktion der Medien aus - wenn auch in unterschiedlicher Art und Weise, in Abhängigkeit vom Medientyp. Ein weiterer wesentlicher Punkt, der im Rahmen der Auswertung zu Tage trat, ist die Dringlichkeit einer differenzierteren Betrachtungsweise alternativer Nachrichtenmedien. Wenngleich als kleinster gemeinsamer Nenner die Funktion einer Vierten Gewalt festgehalten werden kann, muss diese medientypisch betrachtet werden. Als wesentliche Unterscheidungsmerkmale dieser «Typen» alternativer Nachrichtenmedien können die Kategorien «Ökonomische Strukturen», also die Finanzierung der Medien, «Soziale Strukturen», bezugnehmend auf die Akteurskonstellationen (Journalist_innen und Rezipient_innen), wie auch «Medieninhalte» herangezogen werden. Letztere Kategorie lässt sich zudem anhand der Subkategorien «Selbst- und Journalismusverständnis», «Themen» und «Rhetorik/Symbolik» weiter differenzieren. Diese Kategorien erwiesen sich bereits im axialen Kodierprozess als massgeblich, um das Phänomen der alternativen Nachrichtenmedien zu beschreiben. Weiter zeigt die Mehrdimensionalität innerhalb der einzelnen Kategorien die Kontraste zwischen einzelnen (alternativen) Medientypen am deutlichsten. Die nachfolgende Abbildung 5 veranschaulicht das entwickelte Analyseraster zur Beschreibung alternativer Nachrichtenmedien: 
Abbildung 5: Schlüsselkategorie "Alternative Nachrichtenmedien als Vierte Gewalt» und Definitionskategorien alternativer Nachrichtenmedien (Eigene Darstellung)

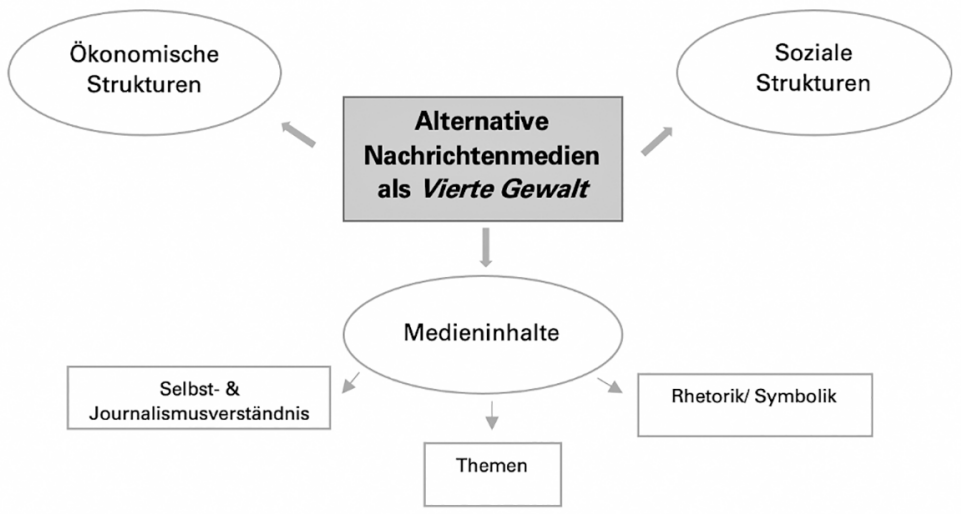

Insgesamt wurden vier Typen alternativer Nachrichtenmedien im DACH-Raum identifiziert, wobei sich ein Typ auf Regularitäten hinsichtlich einer der in Abbildung 5 festgehaltenen Kategorien bezieht und sich durch eine dahingehende Kontrastierung von anderen Typen unterscheidet. Wie häufig bei typologischen Unterscheidungen, sind auch Mischtypen im Datenmaterial denkbar. Die Typen wurden wie folgt bezeichnet:

I «Aufdecker der Mainstreamlügen»

II «Verschwörung und Spiritualität»

III «Aufstand der Zivilgesellschaft»

IV «Die seriöse Alternative»

Die Bezeichnung der Typen sollte allerdings nicht als normative Wertung gedeutet werden, sondern vielmehr als Ausdruck des subjektiven Sinns der Nachrichtenmedien. Weiter wird ob des Forschungsdesigns keine Quantifizierung der jeweiligen Typen vorgenommen, da das Ziel der Analyse in einer theoretischen Sättigung bestand, um eine Generalisierung der Typen zu gewährleisten, und nicht in einer abschliessenden «Vollerhebung». Dennoch muss an dieser Stelle erwähnt werden, dass Typ I «Aufdecker der Mainstreamlügen» besonders präsent im analysierten Datenmaterial erschien (in über der Hälfte der analysierten Websites) und Typ II «Verschwörung und Spiritualität» zum Teil Überschneidungen respektive Vermischungen mit Typ I aufweist. Einen geringen Stellenwert nahmen hingegen - zumindest im hier analysierten Material - Typ III «Aufstand der Zivilgesellschaft» und Typ IV «Die seriöse Alternative» ein. 
In den folgenden Unterkapiteln wird die typologische Unterscheidung ausgeführt. Dafür werden die Typen nacheinander beschrieben und anhand von Ausschnitten des empirischen Materials veranschaulicht.

\section{VII.2.3.1 Typ I: «Aufdecker der Mainstreamlügen»}

Der am häufigsten im analysierten Datenmaterial identifizierte Typ spiegelt gleichzeitig jene Alternativmedien wider, die im aktuellen Forschungsstand hauptsächlich diskutiert werden (vgl. Kapitel III.4). Es handelt sich dabei um jene Medien, die in ihrer Fremdbeschreibung mit dem Thema Desinformation («Fake News») und Rechtspopulismus in Verbindung gebracht werden. Folgend wird zunächst auf die Medieninhalte dieses Typs eingegangen, bevor im Anschluss die ökonomischen und sozialen Strukturen erläutert werden.

\section{Medieninhalte - Selbst- und Journalismusverständnis}

Die «Alternative» dieses Medientyps verdeutlicht sich im Selbst- und Journalismusverständnis. Die Bezeichnung «Aufdecker der Mainstreamlügen» impliziert dabei wesentliche Elemente, die im empirischen Material identifiziert werden konnten. Sowohl in dezidierten Selbstbeschreibungen (z. B. «Über uns») als auch an weiteren Stellen der Website (z. B. Startseite; Subseiten der Website, die Aufschluss über die journalistische Ausrichtung des Mediums geben) wird häufig der Begriff «Mainstream» eingesetzt. Was unter dieser Begrifflichkeit zu verstehen ist, erscheint dabei wie vorausgesetzt. So beschreibt sich beispielsweise die Website PI-News Politically Incorrect im Copyright mit dem Untertitel «News gegen den Mainstream ${ }^{10}$ oder die deutsche Ausgabe des Online-Medium Russia Today als «Informationsquelle jenseits des Mainstreams»" ${ }^{11}$. Unter «Mainstream» sind dabei vorwiegend etablierte Leitmedien $\mathrm{zu}$ verstehen, von denen sich der hier beschriebene Medientyp deutlich abzugrenzen versucht. So kann die Abgrenzung zwischen «Alternative» und «Mainstream» aus Sicht der analysierten Alternativmedien im Sinne einer binären Logik anstatt eines kontingenten Spektrums interpretiert werden. Vielmehr ist eine «Gut-vs.-Böse»-Semantik wiederzufinden (was sich eindrücklich in der Bezeichnung des Mediums Achgut.com ${ }^{12}$, abgekürzt für «Die Achse des Guten», zeigt). «Mainstreammedien» wird Unwahrhaftigkeit in Form des Verbreitens von Lügen vorgeworfen (Stichwort «Lügenpresse»), was bei einigen Websites anhand von eigens dem Thema gewidmeten Subseiten, meist betitelt als «Fake News», ersichtlich wird. Als Beispiel sei hier die Website PI-News genannt, die an passender Stelle auch von «deutscher Lügenpresse» ${ }^{13}$, mit Ver-

\footnotetext{
10 http://www.pi-news.net (Stand: 15.01.2020)

11 https://deutsch.rt.com/uber-uns/(Stand: 15.01.2020)

12 https://www.achgut.com (Stand: 15.01.2020)

13 http://www.pi-news.net/category/altmedien/fake-news/ (Stand: 08.01.2019)
} 
weis auf den öffentlich-rechtlichen Rundfunk und andere Leitmedien, spricht. Ähnlich geht die österreichische Website Unzensuriert vor, die auf Artikel mit dem Schlagwort «Fake News» verlinkt und «ORF-Eklats» und Lügen politischer Parteien (z. B. «Peinlich: SPÖ-Kärnten erfindet Kickl-Aussage») anprangert, die vorwiegend am linken Spektrum anzusiedeln sind ${ }^{14}$. Neben Medien werden auch politische (Regierungs-)Parteien dem Mainstream zugeordnet. Dabei positionieren sich die diesem Typ zugeordneten alternativen Nachrichtenmedien als «Aufdecker» dieser Lügen bzw. Verheimlichungen von Informationen, die von öffentlichem Interesse sind, so z. B. Russia Today: «Unser Leitbild lautet: «Wir zeigen den fehlenden Teil zum Gesamtbild. Also genau jenen Part, der sonst verschwiegen oder weggeschnitten wird.» ${ }^{15}$ Oder auch die Epoch Times, die sich selbst als «frei von Propaganda und Medienzensur $»^{16}$ beschreibt. Alternativmedien des Typs 1 können entsprechend als selbst ernannte «Media-Watchdogs» bezeichnet werden, die sich selbst zum Ziel setzen, Unwahrheiten des medialen und politischen Establishments aufzudecken, diese im Sinne einer Vierten Gewalt zu kritisieren und zu kontrollieren und potenzielle Manipulationsversuche (z. B. in Form von Zensur) durch die herrschende Öffentlichkeit nachzuweisen (so auch die NachDenkSeiten in ihrem Selbstverständnis: «Die NachDenkSeiten beschreiben die vielfältigen Manipulationsversuche sowie Kampagnen und Strategien der Meinungsmache» ${ }^{17}$ ).

Neben dieser Kritik- und Kontrollfunktion versuchen sich Alternativmedien des Typs I auch durch ihr Journalismusverständnis vom «Mainstream» abzugrenzen. Dabei werden häufig etablierte journalistische Standards selbst beansprucht und den klassischen Leitmedien entzogen oder diesen wird zumindest unterstellt, diese Standards nicht zu erfüllen. In diesem Zusammenhang wird beispielsweise Unabhängigkeit in der journalistischen Berichterstattung betont (wie auch bei anderen Alternativmedientypen, wenn auch in unterschiedlicher Ausgestaltung). Unter Unabhängigkeit in diesem Kontext ist einerseits die politische Unabhängigkeit im Sinne freier Meinungsäusserung zu verstehen (z. B. Info-DIREKT: «Es [das Magazin] ist dabei grundsätzlich unabhängig von politischen Parteien, Institutionen und Interessengruppen. ${ }^{18}{ }^{18}$, oder fisch+fleisch: «fisch+fleisch ist eine private Initiative und von Parteien und sonstigen Interessenverbänden gänzlich unabhängig $\left.»^{19}\right)$. Es werden demokratische Werte angesprochen (z. B. Meinungsfreiheit,

14 https://www.unzensuriert.at/?s=fake+news (Stand: 14.11.2018)

15 https://deutsch.rt.com/uber-uns/ (Stand: 15.01.2020)

$16 \mathrm{https} / / /$ www.epochtimes.de/thema/epoch-times/epoch-times-epochtimes-a4717.html (Stand: 14.11.2018)

17 https://www.nachdenkseiten.de/?p=48676 (Stand: 15.01.2020)

18 https://www.info-direkt.eu/ueber-info-direkt/ (Stand: 15.01.2020)

19 https://www.fischundfleisch.com/fuf/ueber-uns (Stand: 15.01.2020) 
pluralistische Gesellschaft, argumentbasierte Diskussion), die allerdings mit der eigenen Berichterstattung in Widerspruch stehen können (siehe Medieninhalte - Themen): «Wir treten für Meinungsfreiheit, Pressefreiheit und Versammlungsfreiheit ein, genauso für Glaubensfreiheit und Menschenrechte für alle.» ${ }^{20}$, so die Epoch Times. Meinungsfreiheit wird dabei mit Aussagen konnotiert, die polarisierend oder auch politisch unkorrekt sind, und steht im starken Gegensatz zur leitenden Meinung des «Mainstreams», wie hier vom österreichischen Magazin Info-DIREKT angesprochen: «Selbstverständlich polarisieren unsere Artikel und sind gegebenenfalls polemisch. Wir sind nicht daran interessiert, den Konsens zu stützen, sondern wollen den Dissens und damit die Diskussion befeuern. ${ }^{21}$

\section{Medieninhalte - Themen ${ }^{22}$}

Das Selbstverständnis dieses Medientyps spiegelt sich in den prominent platzierten Themen wider. Im Fokus steht die Kritik, vorwiegend gegenüber der herrschenden Politik, politischen Parteien oder auch einzelnen Politiker_innen wie auch etablierten Leitmedien, dem «Mainstream». So wird im Bereich der «Politik-Kritik» sehr stark personalisiert und die deutsche Bundeskanzlerin Angela Merkel (vor allem im Kontext Migration/Flüchtlinge) thematisiert. Im Zentrum stehen dabei ein wahrgenommenes Scheitern und mangelnde Einsicht hinsichtlich Fehlentscheidungen Merkels. Beispielhaft sei an dieser Stelle ein Artikel von Tichys Einblick ${ }^{23}$ unter dem Titel «Merkel-Dämmerung: Verdrängte Wirklichkeit» genannt, oder ein ähnlicher Beitrag von Jouwatch: «Frau Merkel, wann werden Sie sich bei den Deutschen entschuldigen? ${ }^{24}$. Hier wird die Migrationspolitik von Angela Merkel in einer zynischen Weise diskutiert (z. B. «Mutti lenkt $»^{25}$, wobei die Bezeichnung «Mutti» eine spöttische Konnotation impliziert).

Abgelehnt werden zudem bestimmte politische Ansichten, die auch Indizien darüber geben, welchem politischen Spektrum dieser Medientyp zuzuordnen ist: Obwohl teilweise bewusst negiert wird, dem rechtsradikalen Milieu anzugehören ( WWarum COMPACT kein rechtsradikales Magazin ist ${ }^{26}$ ), lassen sich gleichzeitig Tendenzen erkennen, dass bestimmte politische Ausrichtungen und Parteien ab-

20 https://www.epochtimes.de/thema/epoch-times/epoch-times-epochtimes-a4717.html (Stand: 14.11.2018)

21 https://www.info-direkt.eu/ueber-info-direkt/ (Stand: 15.01.2020)

22 Da methodisch keine artikelbasierte Medieninhaltsanalyse erfolgte, können an dieser Stelle nur thematische Schwerpunkte skizziert werden, die sich im analysierten Material abzeichneten.

23 https://www.tichyseinblick.de/tichys-einblick/merkel-daemmerung-verdraengte-wirklichkeit/ (Stand: 22.11.2018)

24 https://www.journalistenwatch.com (Stand: 14.11.2018)

25 http://www.pi-news.net/2018/08/michel-denkt-wie-mutti-lenkt/ (Stand: 19.08.2018)

26 https://www.compact-online.de/thema/wir-ueber-uns/(Stand 22.01.2020) 
gelehnt bzw. auch unterstützt werden. Beispielsweise sprechen der Preussische Anzeiger wie auch die Junge Freiheit von «Linksextremismus» ${ }^{27}$; häufig findet schlicht eine Abwertung linker (z. B. fisch+fleisch: «Linke sieht überall nur Naz"s $»^{28}$; Unzensuriert: «Linke wollen kritische Medien aushungern» sowie «Linke Hetze» ${ }^{29}$ ) oder grüner Politik (MMnews: «Grüne wollen Deutschland an EU verhökern»») statt. Inhaltlich geht es dabei häufig um eine Ablehnung aufgrund eingeschränkter Sichtweisen, scheinbar übertriebener «Political Correctness» (z. B. «Gender-Neusprech $\aleph^{31}$ ) oder auch in diesem Fall potenzieller Unwahrheiten, die von diesem politischen Spektrum ausgehen (z. B. Jouwatch: «Was fast alle heutigen Politiker so unausstehlich und auch gefährlich macht, das ist ihr utilitaristisches Verhältnis zur Wahrheit ${ }^{32}$ ). Weitere Hinweise auf politische Spektren ergeben sich durch positive Berichte oder Bezugnahmen (z. B. in Form von Verlinkungen auf Websites) auf politische Parteien (in diesem Fall Parteien, die dem rechten politischen Spektrum zuzuordnen sind, wie die FPÖ (Freiheitliche Partei Österreich) oder AfD (Alternative für Deutschland). So verlinkt beispielsweise Unzensuriert auf den YouTube-Kanal der Freiheitlichen Partei Österreich «FPÖ-TV» oder die Politikstube ${ }^{33}$ auf Videos der AfD. Obwohl - wie nicht anders zu erwarten - deutsche Nachrichtenmedien vorwiegend über deutsche Themen berichten, findet sich ein Deutschland-Bezug durchaus auch bei Schweizer und österreichischen Websites, die sich zum Teil auch laut Selbstbeschreibung auf den DACH-Raum in seiner Gänze stützen, wie beispielsweise Alpenparlament ${ }^{34}$ oder Zaronews ${ }^{35}$.

Gleichzeitig äussert sich politische Kritik anhand konkreter Themen (im Untersuchungszeitraum vor allem Migrationskritik), wie anhand unterschiedlicher, prominent platzierter Beiträge zu erkennen ist. Beispielsweise berichtet Unzensuriert in einer eigens dafür erstellten Sub-Seite regelmässig über so be-

27 Z. B. https://www.preussischer-anzeiger.de/2017/09/24/kriminelle-linksextremisten-verprue geln-junges-maedchen/oder https://jungefreiheit.de/politik/ausland/2020/linksextreme-ver hindern-vorlesung-und-verletzen-studenten/ (Stand: 22.01.2020)

28 https://www.fischundfleisch.com/mag-robert-cvrkal/jetzt-auch-belgien-vor-ausstieg-aus-demmigrationspakt-linke-sieht-ueberall-nur-naz-s-51523 (Stand: 14.11.2018)

29 https://www.unzensuriert.at/content/0028226-linke-hetze-gegen-kritische-journalisten-istunertraeglich (Stand: 12.11.2018)

30 https://www.mmnews.de/politik/118822-gruene-deutschland (Stand: 14.03.2019)

31 https://www.epochtimes.de/meinung/geschlechtergerechte-personenbezeichnung-deut scher-rechtschreibrat-befasst-sich-erneut-mit-gender-neusprech-a2708996.html (Stand: 14.11. 2018)

32 https://www.journalistenwatch.com (Stand: 14.11.2018)

33 https://politikstube.com/ (Stand: 29.01.2020)

34 http://www.alpenparlament.com (Stand: 22.01.2020)

35 https://www.zaronews.world (Stand: 22.01.2020) 
zeichnete «Einzelfälle» ${ }^{36}$, um zynisch auf wiederholte Gewaltfälle ausgehend von Migrant_innen hinzuweisen. Asylsuchende werden weiter in diesem breiteren Kontext als unehrlich und betrügerisch ("Asylbetrüger ${ }^{37}$ ) bezeichnet und entsprechend negativ bewertet.

Die Kritik am medialen «Mainstream», also klassischen Leitmedien, stellt einen weiteren wesentlichen inhaltlichen Schwerpunkt dar, der bereits im vorangegangenen Abschnitt (Medieninhalte - Selbst- und Journalismusverständnis) erläutert wurde.

\section{Medieninhalte - Rhetorik/Symbolik}

Auch anhand des Schreibstils bzw. der Rhetorik kann eine Unterscheidung von klassischen Leitmedien festgestellt werden. Das selbstbeschriebene Ziel freier Meinungsäusserung spiegelt sich dabei nicht unbedingt in klassisch journalistischen Standards wie Objektivität wider. Wie bereits in der Themenwahl erörtert, handelt es sich häufig um eine wertende Berichterstattung, was durch ironische und zynische Elemente sowie überspitzte Formulierungen verdeutlicht wird. So wird beispielsweise das Wort «Flüchtlinge» häufig unter Anführungszeichen gesetzt $^{38}$, um damit zum Ausdruck zu bringen, dass es sich bei dem Grossteil der Asylwerber_innen um keine Flüchtlinge im eigentlichen Sinn handele, sondern sich diese schlicht ein besseres Leben, z. B. in Deutschland, erhoffen würden. In ähnlicher Weise fallen z. B. auch die Begriffe «Gutmenschen $»^{39}$ oder «Einzelfälle» ${ }^{40}$ in zynischer Konnotation. Die ironisch verwendete Bezeichnung «Gutmensch» wird dabei im Kontext des Flüchtlingsdiskurses für jene Menschen verwendet, die sich in ausgeprägter, empathischer Art und Weise für das Wohl von Ärmeren sorgen und für Political Correctness einsetzen (Duden, 2020), was gerade von Rechtspopulist_innen ins Lächerliche gezogen wird. «Einzelfälle» bezieht sich in ironischer Weise auf von Migrant_innen begangene Gewaltdelikte (häufig Sexualdelikte), die laut dieses Medientyps vom «Mainstream» verschwiegen oder als Ausnahmefälle bezeichnet würden, obwohl es (der eigenen Berichterstattung folgend) eine Vielzahl dieser Verbrechen gebe ${ }^{41}$.

36 https://www.unzensuriert.at/category/einzelfaelle/ (Stand: 22.01.2020)

37 Z. B. http://www.pi-news.net/2017/08/die-tricks-der-asylbetrueger/ (Stand: 22.01.2020)

38 Z. B. https://www.journalistenwatch.com/2020/01/18/wdr-welt-deutschland/ (Stand: 20.01. 2020)

39 Z. B. https://www.info-direkt.eu/2018/11/09/sachsen-als-zufluchtsort-fuer-gutmenschen/ (Stand: 29.01.2020)

40 Z. B. in Form einer speziell dafür gewidmeten Unterseite der Website von Unzensuriert: https:// www.unzensuriert.at/category/einzelfaelle/ (Stand: 29.01.2020)

41 Z. B. https://www.unzensuriert.at/content/88637-albanisch-staemmiger-oesterreicher-stachsomalier-fast-tot-prozess (Stand: 29.01.2020) 
Abbildung 6: Aufbau und Layout der Website «Junge Freiheit»" (Deutschland)

Abbildung 8: Aufbau und Layout der Website «Info-DIREKT» ${ }^{44}$ (Österreich)

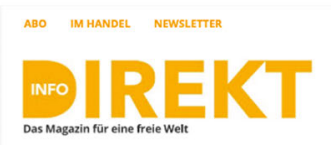

\section{\begin{tabular}{|l|l|l|l|l}
\hline AKTUELLE PRINTAUSGABE & DEUTSCHLAND ÖSTERRICH & STANDPUNKTE / INTERVIEWS & EXTREMISMUS
\end{tabular}}

AKTUELE AUSGABE IM ZETSCHRIFENHANDEL INFO-DIREKT ABONNIEREN SPENDEN FOLGE UNSAUF TELEGRAM:

Abbildung 9: Aufbau und Layout der Website «Newskritik» ${ }^{45}$ (Schweiz)

NEWSSKRITIK

Hauptnews Auslandsnews

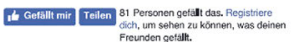

Anmelden

Registrieren

Auffallend bei diesem Typ alternativer Nachrichtenmedien ist der hohe Professionalisierungsgrad bei der Gestaltung der Layouts der Websites. Eine «alternative» Darstellungsform lässt sich bei diesem Typ entsprechend nicht finden; vielmehr wird der Eindruck erweckt, dass professionelle, etablierte Leitmedien imitiert

42 Screenshot von https://jungefreiheit.de (Stand: 16.01.2020)

43 Screenshot von https://www.tichyseinblick.de (Stand: 16.01.2020)

44 Screenshot von https://www.info-direkt.eu (Stand: 16.01.2020)

45 Screenshot von https://www.newskritik.com (Stand: 14.03.2019) 
werden. ${ }^{46}$ Aus Nutzer_innensicht ist daher - rein optisch - kaum identifizierbar, ob es sich um ein professionelles Leitmedium oder ein alternatives Nachrichtenmedium handelt. Die Abbildungen 6 und 7 zeigen die optische Aufbereitung und die thematischen Untergliederungen zweier sehr resonanzreicher (in Form von Nutzer_innenzugriffen) Alternativmedien (Junge Freiheit, Tichys Einblick), die diesem Typ zugeordnet werden. Diese beiden Beispiele ähneln sich in vielfältiger Weise: Prominent platziert ist jeweils der Titel des Mediums, der allerdings sehr schlicht (auch hinsichtlich der farblichen Gestaltung) gehalten ist. Beide Seiten verfügen über ein Suchfeld im oberen Homepage-Bereich, um über Stichworte Inhalte finden zu können. Der Anmelde-Button rechts oben bei der Jungen Freiheit deutet auf das Bestehen einer Gemeinschaft/Community hin, die das Medium nutzt und potenziell dafür bezahlt (Abonnement). Ein ähnliches Bild ergibt sich auch bei Tichys Einblick, bei dem neben Social-Media-Verlinkungen auch ein Aufruf zur (finanziellen) Unterstützung platziert ist. Bei beiden Websites lässt sich eine thematische Ordnung einzelner Seiten finden: Diese orientieren sich vor allem im Fall der Jungen Freiheit an Ressorts, die aus Leitmedien bekannt sind (Politik, Wirtschaft, Kultur). Tichys Einblick setzt hier stärker auf Kategorien, die auf subjektive Sichtweisen (z. B. Tichys Einblick, Kolumnen, Meinungen), aber auch auf bekannte Ressorts (Wirtschaft) hinweisen.

Auch Newssites mit geringeren Nutzerzahlen weisen eine ähnliche - am «Mainstream» orientierte - Optik auf (vgl. Abbildung 8 Info-DIREKT und Abbildung 9 Newskritik). Hier finden sich ebenfalls zentral am oberen linken Teil der Website der Titel respektive das Logo des Mediums und auf der rechten Seite Social-Media-Verlinkungen und/oder Anmeldebuttons. Unter dem Titel stehen jeweils die Ressorts/Themen, die in dem Medium behandelt werden.

Die selbstbeschriebene «Alternative» offenbart sich im Übrigen nicht zuletzt häufig in der Namensgebung der Medien. Jouwatch ${ }^{47}$, abgekürzt für Journalistenwatch, verdeutlicht die Media-Watchdog- respektive Kritik- und Kontrollfunktion dieses Typs alternativer Nachrichtenmedien, ebenso wie das Schweizer Medium Newskritik ${ }^{48}$. Weiter wird die alternative journalistische Ausrichtung verdeutlicht: Unzensuriert impliziert gleichbedeutend, dass Medien existieren, die einer «Zensur» unterworfen sind (ein näherer Blick auf das Selbstverständnis bestätigt die bereits erörtere Annahme, dass damit klassische Leitmedien gemeint sind). GegenARGUMENT.at ${ }^{49}$ lässt eine binäre «Wir-gegen-die-anderen»-Denkweise, unterstützt durch die Unterschrift «Die politisch nicht korrekte Seite für kriti-

\footnotetext{
46 Dennoch ist in diesem Zusammenhang anzumerken, dass die Visualisierung der Medien auch von den finanziellen Ressourcen abhängt (siehe «Ökonomische Strukturen»).

47 https://www.journalistenwatch.com (Stand: 16.01.2020)

48 https://www.newskritik.com (Stand: 14.03.2019)

49 http://www.gegenargument.at (Stand: 16.01.2020)
} 
sche Geister», erkennen, ebenso die bereits erwähnte Achse des Guten Achgut.com. Dabei wird politische Unkorrektheit positiv konnotiert, da laut dieses Typs alternativer Medien politische Korrektheit des Mainstreams mit dem Verschweigen von relevanten, die Öffentlichkeit betreffenden Informationen einhergehe. Dies zeigt sich eindrücklich bereits in der Betitelung des Mediums PI-News Politically Incorrect.

\section{Soziale Strukturen}

Die «sozialen Strukturen» beziehen sich auf die Akteurskonstellationen der Medien dieses Typs («Aufdecker der Mainstreamlügen»), worunter der Professionalisierungsgrad der Medien zu verstehen ist. Einerseits wird die Produzierendenseite der (Laien-)Journalist_innen/Redaktion betrachtet, andererseits die Seite des adressierten Publikums. In diesem Zuge wird wiederum auf Selbstauskünfte auf den Websites verwiesen bzw. auf Strukturen (wie z. B. Organisation der Redaktion), die auf den Seiten ablesbar sind. Generell kann bei diesem Medientyp von einem hohen Professionalisierungsgrad gesprochen werden: Aus Sicht der Medienschaffenden existieren viele Indizien dafür, dass bei weitem nicht nur Lai_innen und Pseudo-Journalist_innen Beiträge publizieren, sondern auch ausgebildete Journalist_innen, vor allem auf jenen Webseiten mit hohen Reichweiten im Sinne von Nutzer_innenzahlen (in Form von Seitenzugriffen, vgl. Kapitel VII.1). Als Beispiel sei hier die Junge Freiheit erwähnt, die in der Sparte «Blick in die Redaktion ${ }^{50}$ auf das Renommee ihrer Redakteur_innen verweist, ausgedrückt durch Kurzbiographien mit häufigem Verweis auf Studienabschlüsse dieser; ähnliches gilt für Achgut.com («Unsere Liste der Guten» ${ }^{51}$ ). Ähnlich weisen auch weitere Medien dieses Typs in deren Selbstbeschreibungen ausdrücklich auf ihre Redaktion hin (z. B. EpochTimes, Schweizerzeit ${ }^{52}$ ). Eine genaue Auflistung der Autor_innen und deren Biographien sowie Darstellungen von Redaktionen drücken Seriosität aus, zumal klassische Informationsmedien ebendiese Informationen auf ihren Websites zur Verfügung stellen. Dennoch ist bei diesem Typ das Spektrum an Journalist_innen breiter zu fassen, da durchaus auch Lai_innen als Autor_innen fungieren oder explizit «Gastjournalist_innen» angesprochen werden, Beiträge einzusenden (z. B. fisch+fleisch, erstaunlich.at ${ }^{53}$, Politikstube).

Die Leser_innenschaft dieses Medientyps orientiert sich am Selbstverständnis der Medien. Infolgedessen richtet sich dieser Typ vor allem an kritische Le-

\footnotetext{
50 https://jungefreiheit.de/informationen/blick-in-die-redaktion/ (Stand: 29.01.2020)

51 https://www.achgut.com/autoren (Stand 29.01.2020)

52 https://schweizerzeit.ch/ (Stand: 29.01.2020)

53 http://erstaunlich.at/index.php?option=com_content\&view=article\&id=6\&ltemid=5 (Stand: 29.01.2020)
} 
ser_innen, die dem «Mainstream» misstrauen (siehe Abschnitt «Selbst- und Journalismusverständnis»).

\section{Ökonomische Strukturen}

Die ökonomischen Strukturen (die Art, wie sich die Medien finanzieren) sind oft schwierig anhand der Selbstauskunft auf den Websites in Erfahrung zu bringen. Dennoch gibt es Indizien dafür, wie die Medien zu finanziellen Mitteln kommen. Dies ist vor allem deswegen von Interesse, da frühere Definitionen von «Alternativmedien» insbesondere auf deren Non-Profit-Ausrichtung verweisen (Atton, 2011). Beinahe bei allen analysierten Medien (und auch bei den anderen Medientypen) ist dies nicht der Fall, das heisst es zeigen sich Indizien einer Gewinnorientierung. Dabei ist der Kommerzialisierungsgrad bei diesem Typ I besonders ausgeprägt. So finden sich auf den Websites Spendenaufrufe oder Aufrufe zur «Unterstützung». Ein Klick auf das «Unterstützen-Sie-uns»-Feld (z. B. bei NachDenkSeiten) oder «Spenden»-Feld (z. B. bei Journalistenwatch) leitet hierbei auf die Kontoverbindung des Medientitels. Oder aber es wird an einer anderen Stelle der Website auf Kontodaten hingewiesen, z. B. am Seitenende oder -rand, wie bei Info-DIREKT oder Freitum ${ }^{54}$. Die Aufforderung zur «Unterstützung» kann gleichzeitig mit einem antizipierten Gemeinschaftsgefühl interpretiert werden. Neben kostenlosen Newslettern werden teilweise auch kostenpflichtige Abonnements angeboten (in Print oder digital), etwa bei der Jungen Freiheit oder Tichys Einblick, was auf eine starke Professionalisierung hinweist. Reichweitenstarke Websites (bezogen auf die monatlichen Nutzer_innenzugriffe, z. B. EpochTimes, Journalistenwatch, Achgut.com, Deutsche Wirtschaftsnachrichten ${ }^{55}$ etc.) betten ausserdem Werbung (Anzeigen, Videos, die nicht mit den eigenen Inhalten in Verbindung stehen) in ihre Website ein, während andere Alternativmedientypen (z. B. Typ IV «Die seriöse Alternative») Werbung dezidiert ablehnen.

Zusammenfassend kann Typ I «Aufdecker der Mainstreamlügen» als der präsenteste Alternativmedientyp im deutschsprachigen Raum betrachtet werden. Dieser richtet sich vor allem gegen die Berichterstattung des «Mainstreams» aus Politik und Medien und geht davon aus, dass dieser aus absichtlichen Falschmeldungen respektive Lügen besteht, die es aufzudecken gilt. Der Medientyp agiert dabei häufig hoch professionalisiert, was sich nicht nur in der visuellen Gestaltung niederschlägt, sondern auch im personellen Aufbau, der an klassische Redaktionen erinnert. Ebenso wird über unterschiedliche Wege für eine entspre-

54 http://www.freitum.de (Stand: 29.01.2020)

55 https://deutsche-wirtschafts-nachrichten.de (Stand: 29.01.2020) 
chende Finanzierung gesorgt, beispielsweise durch Spenden, Abonnements oder Werbungen.

Der nachfolgend beschriebene Alternativmedientyp hängt eng mit diesem zusammen, weshalb einige Überschneidungen zwischen den beiden Typen festgestellt werden können. Dennoch unterscheiden sie sich in einigen wesentlichen Punkten (z. B. bezüglich der Rahmung der Beiträge), was eine typologische Unterscheidung sinnvoll erscheinen lässt. Zudem impliziert eine jede Typologie Mischtypen, die in der empirischen Wirklichkeit auftreten können.

\section{VII.2.3.2 Typ II: «Verschwörung und Spiritualität»}

Die Bezeichnung dieses Medientyps darf nicht mit einer normativen Bewertung im Sinne eines «Verschwörungstheoretiker»-Vorwurfs verwechselt werden. Vielmehr basiert die Benennung «Verschwörung und Spiritualität» auf den Medieninhalten dieses Typs. Diese werden nachfolgend beschrieben, wobei auch auf die sozialen und ökonomischen Strukturen eingegangen wird.

\section{Medieninhalte - Selbst- und Journalismusverständnis}

Die Media-Watchdog-Funktion, wie sie bei Typ I identifiziert wurde, lässt sich auch bei diesem Typ wiederfinden, allerdings in einer anderen Rahmung. So beschreibt sich Typ II eher als «Geheimnislüfter» von Verschwörungen des so bezeichneten Mainstreams. Dabei ist der Verschwörungsbegriff (wie im Forschungsstand erörtert, vgl. Kapitel III.4.3) deutlich vom «Fake-News»-Begriff respektive -Vorwurf abzugrenzen: Während Typ I laut Selbstbeschreibung davon ausgeht, dass politische und mediale Eliten bewusst und mit Täuschungsabsicht Falschnachrichten verbreiten, vermutet Typ II hinter diesen potentiellen Lügen eine grössere Verschwörung des Establishments. Es wird postuliert, dass Eliten einen geheimen Plan verfolgen und im Hintergrund die Fäden ziehen würden. Entsprechend sehen sich die zu Wort kommenden Akteur_innen eher als «Geheimnislüfter».

Bezüglich des journalistischen Verständnisses streicht Typ II die politische Unabhängigkeit in Form einer ablehnenden Haltung gegenüber politischen Eliten heraus. Im Vordergrund steht der kritische Umgang mit gesellschaftlichen (insbesondere politischen) Ereignissen und deren Berichterstattung in Leitmedien. Dabei setzen sich Medien dieses Typs zum Ziel, komplexe globale Zusammenhänge verständlich zu machen. KenFM zitiert in diesem Zusammenhang beispielsweise den Autoren George Orwell, der in seinem erfolgreichen Werk «1984» die totale Überwachung und Kontrolle der Gesellschaft prognostizierte und damit eine Art Vordenkerrolle für Produzent_innen dieser Nachrichtenseiten einnimmt: «Journalismus heißt etwas zu drucken, von dem jemand will, dass es nicht gedruckt 
wird. Alles andere ist Public Relations. ${ }^{56}$ Alternativmedien des Typs II verstehen sich dementsprechend selbst als Journalist_innen, die Dinge aufdecken, die von anderen Akteur_innen verschwiegen werden. Gleichzeitig wird dadurch eine Abgrenzung zum kritisierten «Mainstream» deutlich, indem diesem der Vorwurf des Verdeckens von Ereignissen gemacht wird.

\section{Medieninhalte - Themen}

Ähnlich wie bei Typ I steht die Ablehnung politischer und medialer Eliten auch bei diesem Medientyp im Vordergrund. Als wesentlicher Unterschied ist die Tatsache hervorzuheben, dass im Vergleich zu Typ I nicht dezidiert das politisch linke Spektrum kritisiert oder diffamiert wird, sondern eine generelle Elitenkritik vorherrschend ist. Diese Kritik besteht vorwiegend unter der Annahme der Websiteproduzent_innen, dass es eine Verschwörung von Eliten gebe, die für gesellschaftliche Ereignisse, wie beispielsweise Krisen (z. B. die «Flüchtlingskrise», 9/11 etc.), verantwortlich seien und diese bewusst herbeiführen würden. Es wird davon ausgegangen, dass unterschiedliche Begebenheiten miteinander in Verbindung stehen und Teil einer grösseren Verschwörung sind. Die Medieninhalte bestehen demnach hauptsächlich aus Berichten über lokale und globale, vorwiegend politische und wirtschaftliche Themen, die im Kontext einer dahinterliegenden Verschwörung erörtert werden. Dabei scheinen die Medienmacher_innen vor allem das Ziel zu verfolgen, Leser_innen von den vermeintlichen Verschwörungen, also Deutungen von Kausalzusammenhängen innerhalb und zwischen gesellschaftlichen Ereignissen, zu überzeugen. So schreibt beispielsweise der Hauptautor von Alles Schall und Rauch, der unter dem Namen «Freeman» Beiträge veröffentlicht, im Rahmen seiner so bezeichneten «Spielregeln» (im Sinne einer Selbstbeschreibung der Newswebsite): «Für die Skeptiker unter euch, die nicht an Verschwörungen glauben, empfehle ich meinen Artikel «Die Phsychologie [sic!] der Leugnung> zu lesen. ${ }^{57}$ Folglich geht der Autor davon aus, dass Leser_innen nur dann der eigenen Berichterstattung und vermeintlichen Lüftung von Elitenverschwörungen nicht glauben, wenn «Tatsachen» geleugnet werden. Auch die Website $M M n e w s^{58}$ verweist auf der Startseite auf «Bewiesene Verschwörungstheorien» im Sinne einer dahingehenden Überzeugung des Publikums.

Unter den thematisierten Verschwörungen sind neben aktuellen Ereignissen (zum Erhebungszeitpunkt vorwiegend die Themen «Migration» und «Flüchtlingspolitik») auch frühere Theorien und Reporte zu bestimmten Themen zu finden. Es handelt sich hierbei um eine Art «Verschwörungs-Klassiker», die unabhängig

56 https://kenfm.de/ueber-kenfm/ (Stand: 27.02.2020)

57 http://alles-schallundrauch.blogspot.com/2007/10/kommentar-spielregeln.html (Stand: 04.03.2020)

58 https://www.mmnews.de (Stand: 04.03.2020) 
von der jeweiligen Website omnipräsent in der Community erscheinen, wie beispielsweise die bereits erwähnte Verschwörung rund um den Einsturz der Türme des World Trade Centers am 11. September 2001, die «Rothschild-Verschwörung» ${ }^{59}$ (wonach die Bank-Dynastie die Welt beherrsche) oder die Verschwörung Schweizer und deutscher Medienhäuser, die angeblich u. a. von der NATO oder dem Bilderberg-Netzwerk ${ }^{60}$ gesteuert werden ${ }^{61}$. Die Stories dahinter werden nicht nur in Textform erörtert, sondern häufig auch in Form von Videos, wie etwa sehr prominent im Fall von KenFM oder Alpenparlament.tv.

Neben dem Thema «Elitenverschwörung» finden sich auf den Websites dieses Medientyps viele esoterische, spirituelle Medienbeiträge, im Fall der Website Alpenschau.com ${ }^{62}$ sogar innerhalb einer eigenen Rubrik/Subseite. Der Fokus liegt dabei vorrangig auf dem Gesundheitsbereich, wobei gleichzeitig klassische, alltagsweltliche und medizinische Praktiken (im Sinne eines «Mainstreams»), wie beispielsweise die Pharma-Industrie, übliche Krebstherapien, u. Ä., kritisiert werden. ${ }^{63}$ Die beiden Schwerpunktthemen «Verschwörung» und «Spiritualität» sind insofern in sich stimmig, als in beiden die Suche nach der (absoluten) Wahrheit im Vordergrund steht. Dabei wird auch der Eindruck erweckt, dass es Dinge jenseits offizieller Erklärungen gibt, wie beispielsweise übernatürliche Phänomene (z. B. Kornkreise $\left.{ }^{64}\right)$.

\section{Medieninhalte - Rhetorik/Symbolik}

Sprachliche und rhetorische Auffälligkeiten orientieren sich stark an den sozialen Strukturen dieses Medientyps, zumal die Produzent_innenseite hauptsächlich aus Lai_innen besteht (siehe Abschnitt «Soziale Strukturen»). Journalistische Qualitätskriterien wie Wertfreiheit oder Quellentransparenz spielen dementsprechend eine geringe Rolle, auch der Schreibstil ist vorwiegend laienhaft. Die Inhalte selbst sind zudem häufig im Videoformat aufbereitet. Ähnlich wie bei Typ 1 wird die Medienberichterstattung klassischer Leitmedien zynisch hinterfragt oder ins Lächerliche gezogen (dies ist beispielsweise häufig in Videos von Ken Jebsen, Betreiber der Website KenFM, der Fall). Dabei werden zum Teil auch

59 Z. B. https://www.alpenparlament.tv (Stand: 14.03.2019)

60 Diese Theorie besagt, dass sich an der jährlichen Bilderberg-Konferenz einflussreiche Persönlichkeiten aus den Bereichen Politik, Wirtschaft, Militär, Hochadel u. Ä. (die tatsächlich stattfindet) untereinander die «Welt aufteilen». Der Name «Bilderberg» ist auf das erste Treffen in den 1950er Jahren im «Hotel de Bilderberg» in Oosterbeek zurückzuführen (Kwasniewski, 2012).

61 Z. B. https://uncut-news.ch (Stand: 04.03.2020); vgl. auch die Verlinkung auf https://swprs.org/ netzwerk-medien-schweiz/ (Stand: 04.03.2020)

62 https://alpenschau.com/category/alpenschau/spiritualitaet/ (Stand: 05.03.2020)

63 Z. B. Rubrik «Medizinnews» auf https://www.mmnews.de (Stand: 05.03.2020)

64 https://www.alpenparlament.tv (Stand: 14.03.2019) 
Medienbeiträge des «Mainstreams» aufgezeigt und kritisch hinterfragt. Dass es sich dabei nicht um die Wahrheit handele (oder handeln könne), wird im Laufe der Berichte aufgezeigt; ebenfalls wird antizipiert, dass das potentielle Geheimnis nur aufgrund von Naivität nicht durchschaut werden könne ${ }^{65}$. Weiter werden Begrifflichkeiten wie «Verschwörungstheorien» und «Verschwörungstheoretiker» selbst kritisch reflektiert und als «Kampfbegriffe» interpretiert. So zitiert beispielsweise die Website Rubikon ${ }^{66}$ Prof. Rainer Mausfeld ${ }^{67}$ : «Der politische Kampfbegriff der Verschwörungstheorie lässt sich kurz abhandeln. Er ist ohne jede ernsthafte intellektuelle Substanz und erschöpft sich weitgehend in seiner ideologischen Verwendung als Diffamierungsbegriff». Die Websites dieses Typs lehnen eine Bezeichnung als Verschwörungstheoretiker gleichwohl dezidiert ab (obschon implizit selbst von grösseren Elitenverschwörungen die Rede ist).

Während Typ I optisch stark an den Websites klassischer Leitmedien orientiert ist, erweist sich die antizipierte «Alternative» bei Typ II als visuell wesentlich ausgeprägter. Auf diese Weise wird der Eindruck erweckt, dass allein durch die visuelle Darstellung versucht wird, sich vom «Mainstream abzugrenzen». Das Erscheinungsbild ist z. B. düsterer, wie etwa anhand der Schweizer Seite Alles Schall und Rauch ${ }^{68}$ deutlich wird (vgl. Abbildung 10). Bei diesem konkreten Beispiel wird mit dunklen Farben gearbeitet; das Logo symbolisiert eine Weltkugel, die in Flammen aufgeht. Die Bezeichnung «Alles Schall und Rauch» scheint erneut auf die politische und mediale Öffentlichkeit, den «Mainstream» und dessen (falsche, unwahrhaftige) Berichterstattung zu verweisen. Das Logo deutet gleichzeitig auf den Weltuntergang hin. Prominent platziert ist weiter eine Illustration zum Thema 9/11, also den Terroranschlägen am 11. September 2001, in der die Türme des World Trade Centers die «11» darstellen sollen. ${ }^{69}$ Die Überschrift «Was geschah wirklich am 11. September?» deutet eindrücklich darauf hin, dass der «offiziellen» Berichterstattung etablierter Leitmedien bei diesem konkreten Ereignis nicht geglaubt bzw. vertraut wird und die wahren Begebenheiten aufgedeckt werden müssen. Auch die Seitenüberschriften bzw. -kategorien stimmen nicht mit den

65 Z. B. https://kenfm.de/me-myself-and-media-53/ (Stand: 05.02.2020)

66 https://www.rubikon.news/artikel/das-totschlagargument (Stand: 27.02.2020)

67 Rainer Mausfeld ist emeritierter Professor für Allgemeine Psychologie an der Universität Kiel (https://www.uni-kiel.de/psychologie/mausfeld/, Stand: 27.02.2020). In konspirativen Kreisen wird Mausfeld häufig als «Elitenkritiker»zitiert (https://www.rubikon.news/autoren/rainermausfeld, Stand: 27.02.2020).

68 https://alles-schallundrauch.blogspot.com (Stand: 29.01.2020)

69 Rund um die Terroranschläge am 11. September kursiert eine Vielzahl an Verschwörungstheorien, z. B., dass die US-Regierung von den Anschlägen gewusst und bewusst nichts dagegen unternommen habe (vgl. z. B. http://alles-schallundrauch.blogspot.com/search/label/9\%2F11, Stand 29.11.2020). 
aus den Leitmedien bekannten kategorischen Einteilungen (z. B. nach Ressorts) überein, sondern werden selbst definiert (z. B. «Regeln», «Stammtisch»).

Abbildung 10: Layout der Website «Alles Schall und Rauch» ${ }^{70}$ (Schweiz)

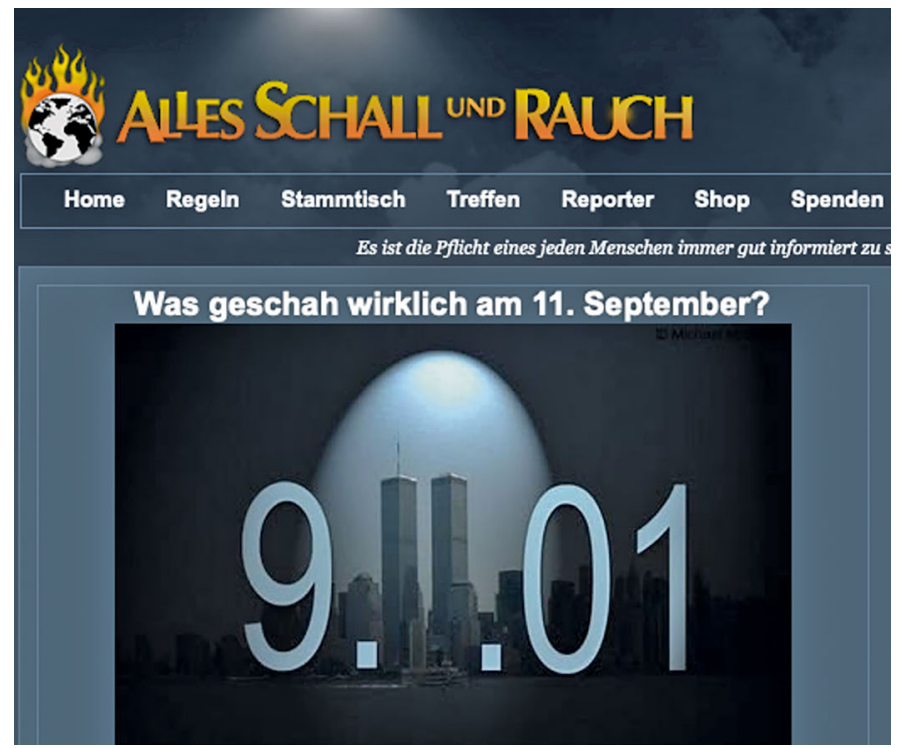

Auch die Website Uncut News ${ }^{71}$ (vgl. Abbildung 11), ebenfalls Schweizer Ursprungs, arbeitet mit dunklen Farben; der Titel ist bewusst in unklaren Lettern auf schwarzem Hintergrund platziert. Eine Kategorisierung existiert auf dieser Seite überhaupt nicht; die Beiträge sind in Kästen untereinander angeordnet. Im Hintergrund der gesamten Website erscheint eine Weltkugel. Die Weltmetapher, die sich sowohl bei dieser Seite als auch bei der eben besprochenen Website Alles Schall und Rauch wiederfindet, kann mit der Annahme, dass Weltereignisse miteinander in Zusammenhang stehen, interpretiert werden (nicht umsonst wird von «Weltverschwörung» gesprochen).

70 Screenshot von http://alles-schallundrauch.blogspot.com (Stand: 14.03.2019)

71 https://uncut-news.ch (Stand: 05.02.2020) 


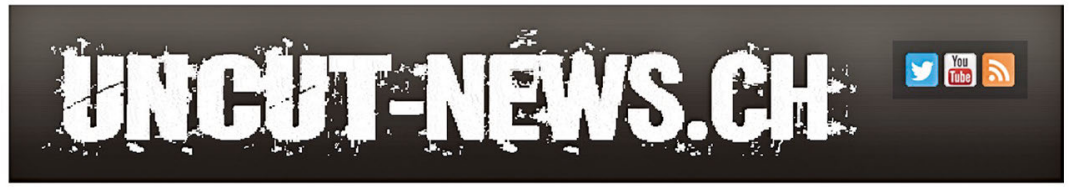

Die alternative Darstellungsform dieses Alternativmedientyps muss allerdings nicht unbedingt finster sein, obgleich auch in den Medieninhalten selbst, häufig in Form von Videos, stark mit Düsterkeit (sowohl in der visuellen Darstellung als auch in der musikalischen Rahmung) gearbeitet wird, so z. B. bei KenFM. Ganz im Gegenteil konnten auch Websites mit hellen, «erleuchtenden» Farbcodes identifiziert werden ${ }^{73}$, was gleichzeitig den zweiten präsenten thematischen Fokus dieses Medientyps widerspiegelt, nämlich Spiritualität und Esoterik.

\section{Soziale Strukturen}

Über die Produzent_innen der Webseiten dieses Medientyps ist im Vergleich zu Typ I wenig bekannt; insofern sind diese deutlich weniger professionell ausgerichtet. Es handelt sich vorwiegend um Lai_innen, die sich nicht immer namentlich erkenntlich zeigen. Weiter können auch pseudojournalistische Akteur_innen identifiziert werden, die ihre eigene Persönlichkeit - z. B. im Fall von Ken Jebsen - im Gegenteil sogar äusserst stark herausstreichen. Die Webseite KenFM ist stark auf eine Person fokussiert (obgleich es eine längere Liste an Autor_innen gibt), z. B. ersichtlich anhand der YouTube-Videoreihe «Me, Myself and Media» ${ }^{74}$. Ebenso prominent platziert sind Jebsens Diskussionen mit unterschiedlichen, aber gleichgesinnten Personen, wobei häufig ein Verweis auf deren wissenschaftliche Expertise erfolgt. Allen Webseiten dieses Typs ist jedoch die vorwiegend pseudojournalistische, laienhafte Ausrichtung gemein.

Der Alternativmedientyp II richtet sich an ein kritisches Publikum (z. B.: «Rubikon ist das Magazin für die kritische Masse. Wir berichten über das, was in den Massenmedien nicht zu finden ist.» ${ }^{75}$ ) im Sinne einer «Aufklärungsarbeit». Wie bereits im Abschnitt «Medieninhalte» erwähnt, wird der Eindruck erweckt, das Publikum von gesellschaftlichen Zusammenhängen und Ereignishintergründen überzeugen $\mathrm{zu}$ wollen. So schreibt beispielsweise KenFM: «Das Verstehen politischer Prozesse steht stets im Fokus der Debatte. Keine Aneinanderreihung verkürzter Statements zum Zwecke der Platzierung marketingorientierter oder

72 Screenshot von https://uncutnews.ch (Stand: 14.03.2019)

73 Z. B. https://alpenschau.com, https://www.alpenparlament.tv (Stand: 05.03.2020)

$74 \mathrm{https} / / / \mathrm{kenfm} . d e / /$ sendungen/me-myself-and-media/ (Stand: 23.11.2020)

75 https://www.rubikon.news/kontakt (Stand: 05.03.2020) 
parteipolitischer Inhalte. Zuschauer werden stattdessen eingeladen, komplexe Ereignisse mit Hilfe der Kompetenz und Erfahrung der Gäste in einen verständlichen umfassenden Zusammenhang einzuordnen.» ${ }^{76}$

\section{Ökonomische Strukturen}

Alternativmedientyp II agiert insofern weniger kommerziell als Typ I, als keine Evidenzen für den Verkauf von Abonnements oder dergleichen gefunden wurden. Dies spiegelt sich gleichzeitig in dem stärker laienhaften, pseudojournalistischen Auftreten wider, das einerseits als bewusster Ausdruck der «Alternative» gedeutet werden kann, oder auch als Resultat mangelnder finanzieller Ressourcen. Trotzdem sind auch bei diesem Alternativmedientyp Aufrufe zur Unterstützung in Form von Spenden sehr präsent. KenFM versteht sich z. B. als Portal «all derer, die uns mit ihrem Geld den Auftrag gegeben haben, im Dreck zu wühlen, die Spreu vom Weizen zu trennen» ${ }^{77}$. Oder Uncut News: «Mit deiner Spende sicherst du unsere Unabhängigkeit» ${ }^{78}$. Die tatsächliche Motivation hinter dem Spendenaufruf ist über die Selbstbeschreibung selbsterklärend nicht identifizierbar. Weiter haben die Websites teilweise Werbungen wie auch Verlinkungen zu anderen Portalen (z. B. MMnews, Alpenschau.com) integriert.

Zusammenfassend lässt sich der hier beschriebene Typ II vor allem dadurch charakterisieren, dass er sich selbst als Geheimnislüfter präsentiert. Dabei wird in Abgrenzung zu Typ I weniger die als lügenhaft antizipierte Berichterstattung von Einzelereignissen kritisiert, als vielmehr die Annahme vertreten, dass es eine «absolute Wahrheit» gebe, gesellschaftliche Ereignisse miteinander in Zusammenhang stünden und von Eliten geplant und gesteuert würden - im Sinne einer grösseren dahinterliegenden Verschwörung. Gleichbedeutend werden auch die Medieninhalte thematisch mit dem Fokus gerahmt, das Publikum über ebendiese Verschwörungen informieren zu wollen. Die Inhalte werden oftmals in Form von selbst gedrehten Videos präsentiert. Die visuelle Gestaltung ist im Gegensatz zu Typ I laienhaft, wodurch bereits durch das Layout die alternative Form deutlich wird. Entsprechend grenzt sich Typ II optisch klar vom klassischen Informationsjournalismus ab und hat beispielsweise ein düsteres Erscheinungsbild, was das Thema «Verschwörung» auch visuell transportiert. Die Produzent_innen der Websites sind Lai_innen und Pseudojournalisten, angesprochen wird ein kritisches Publikum, das es aufzuklären gilt.

76 https://kenfm.de/ueber-kenfm/ (Stand: 05.03.2020)

77 https://kenfm.de/ueber-kenfm/ (Stand: 05.03.2020)

78 https://uncut-news.ch (Stand: 05.03.2020) 


\section{VII.2.3.3 Typ III: "Aufstand der Zivilgesellschaft»}

Typ III ist inhaltlich wie auch strukturell klar von den ersten beiden Alternativnachrichtentypen abzugrenzen. Typ III kann am besten mit den neuen sozialen Bewegungen und Protestgruppen der 1960er- und 1970er-Jahre verglichen werden, weshalb auch die Benennung «Aufstand der Zivilgesellschaft» gewählt wurde. Auch Typ III sieht sich als Opposition gegenüber Eliten, allerdings in einer anderen Form, und vor allem in politischer Hinsicht. Nachfolgend werden die zentralen kategorischen Charakteristika dieses Typus beschrieben.

\section{Medieninhalte - Selbst- und Journalismusverständnis}

Medientyp III identifiziert sich klar mit zivilgesellschaftlichen Akteur_innen und versucht, eine öffentliche «Stimme» dieser einzunehmen. Dieses Kriterium wurde bereits im Rahmen der Aufarbeitung des Forschungsstands über Alternativmedien genannt, wonach die unterrepräsentierte Bevölkerung vertreten werden solle (vgl. Kapitel III.4). Dabei definiert sich Typ III besonders über seine politische Ausrichtung, während eine Opposition gegenüber des etablierten Informationsjournalismus selten bemerkbar ist. Dementsprechend liegt der Fokus auch weniger auf einem alternativen journalistischen Verständnis. Prominenter ist hingegen das politische Selbstverständnis. Anhand der Selbstbeschreibungen wird deutlich, dass Nachrichtenseiten dieses Typs politisch links einzuordnen sind; teilweise definieren sie sich selbst als marxistisch, sozialistisch oder kommunistisch. So schreibt beispielsweise das österreichische Online-Medium mosaik: «Wir bringen Themen aufs Tapet, die in anderen Medien nicht zur Sprache kommen und machen Bewegungen sichtbar, die für eine antirassistische, feministische, ökologische und soziale Wende kämpfen. Wie zeigen solidarische Perspektiven zu tagespolitischen Themen und Alternativen zu autoritärer Wende und Rechtsrutsch auf.» ${ }^{79}$ Ähnlich schreibt auch Der Funke: «Wir sind sozialistisch [...] Wir sind klassenkämpferisch [...] Wir sind revolutionär [...] Wir sind internationalistisch und gegen jede Spaltung der Arbeiterklasse». ${ }^{80}$ Medien dieses Typs sehen sich den Zitaten zufolge als Repräsentant_innen der Arbeiterklasse und vertreten sozialistische Werte. Dabei handelt es sich nicht unbedingt um «neue» Nachrichtenplattformen, sondern teilweise um bereits lang bestehende Nachrichtenangebote, die in sozialen Bewegungen und teils auch politischen Parteien ihren Ursprung finden (z. B. Unsere Zeit ${ }^{81}$, Rote Anneliese ${ }^{82}$ ). Dabei ist die Positionierung einer «Vierten Gewalt» dahingehend ersichtlich, dass Kritik gegenüber politischen, sozialen und ökologischen Missständen geäussert wird: «Die RA versteht sich dabei im aufklärerischen Sinne als

\footnotetext{
79 https://mosaik-blog.at/selbstverstaendnis/ (Stand: 06.03.2020)

80 https://derfunke.at/about/programm (Stand: 06.03.2020)

81 https://www.unsere-zeit.de (Stand: 06.03.2020)

82 http://www.roteanneliese.ch (Stand: 06.03.2020)
} 
Kontrollinstanz zur Exekutive, zur Legislative und zur Judikative. Um diese Kontrollfunktion wahrzunehmen, betreibt die RA einen investigativen Journalismus.» ${ }^{83}$ In Abgrenzung zu den Alternativmedientypen I und II versteht sich Typ III nicht als Aufdecker von Lügen oder geheimen Verschwörungen, sondern thematisiert, kontrolliert und kritisiert gesellschaftliche Missstände, die in Zusammenhang mit politischen Eliten und deren Regierung stehen können.

\section{Medieninhalte - Themen}

Das Selbstverständnis dieses Medientyps spiegelt sich in der thematischen Schwerpunktsetzung wider. Demnach ist primäres Ziel dieses Medientyps, für soziale Gerechtigkeit einzustehen. So betitelt beispielsweise Kontrast eine Headline im Erhebungszeitraum im November 2018: «Diese 3 Fälle zeigen, wie die Abschaffung der Notstandshilfe Existenzen bedroht» ${ }^{84}$, oder «Nur mehr 325 Euro Lehrlingsentschädigung» ${ }^{85}$. Ähnliches zeigt sich bei der Onlineseite Der Funke, auf der beispielsweise der Aufruf zu einer «ArbeiterInnenpartei» gegeben wird oder Themen wie Sexismus, Frauenrechte und Rassismus angesprochen werden. ${ }^{86}$ Die Themen repräsentieren entsprechend allesamt eine Bürger_innennähe. Es geht darum, «politische, soziale und ökologische Missstände» ${ }^{87}$ aufzudecken und «kritische, kämpferische und demokratische Positionen sichtbar [zu] machen ${ }^{88}$. Diese werden schliesslich anhand aktueller Themen dargestellt (wie etwa am Beispiel der Notstandshilfe oder auch aktueller Streiks wie Klima- oder Frauenstreiks ${ }^{89}$ ). Wie bereits erläutert, machen die Medien dieses Typs ihre Standpunkte aus einem politischen linksorientierten Selbstverständnis klar und kritisieren entsprechend rechtsorientierte Politik wie auch kapitalistische Systeme.

\section{Medieninhalte - Rhetorik/Symbolik}

Passend zur thematischen Ausrichtung ist der rhetorische Stil als kämpferisch und mobilisierend einzuordnen. So ist beispielweise der Bereich «Über uns» der Website Der Funke mit der Überschrift «Wofür wir kämpfen» versehen ${ }^{90}$, ähnlich will auch die österreichische Online-Zeitschrift Mosaik «kämpferische Positionen

\footnotetext{
83 http://www.roteanneliese.ch/ueber-die-rote-anneliese/ (Stand: 06.03.2020)

84 https://kontrast.at/diese-3-faelle-zeigen-wie-die-abschaffung-der-notstandshilfe-existenzen-bedroht/ (Stand: 19.03.2020)

85 https://kontrast.at/lehrlinge-ausbildungsgeld-halbiert/ (Stand: 19.03.2020)

86 https://derfunke.at (Stand: 14.03.2019)

87 http://www.roteanneliese.ch/ueber-die-rote-anneliese/ (Stand: 19.03.2020)

88 https://mosaik-blog.at/wie-wir-arbeiten/ (Stand: 19.03.2020)

89 https://derfunke.at (Stand: 14.03.2019)

90 https://derfunke.at/about/programm (Stand: 06.03.2020)
} 
sichtbar machen $»^{91}$. Websites dieses Typs zeigen demnach klar ihre Positionen und Meinungen, die vor allem gegen Kapitalismus oder Missstände in der vorherrschenden Politik gerichtet sind; die Berichterstattung erfolgt demnach den eigenen Zielen entsprechend wertend. Durch Aufrufe zum Mitmachen werden Leser_innen mobilisiert und es wird ein Gemeinschaftsgefühl hergestellt («Tritt uns bei und kämpfe mit uns für eine sozialistische Gesellschaft ${ }^{92}$ ). Dabei ist insofern eine Ingroup- vs. Outgroup-Haltung feststellbar, als sich die Nachrichtenmedien von der hegemonialen Politik distanzieren und Perspektiven «abseits des Mainstreams ${ }^{93}$ aufzuzeigen versuchen. Diesbezüglich existieren jedoch auch aus sprachlicher, rhetorischer Sicht starke Unterschiede im Vergleich zu den ersten beiden beschriebenen Alternativmedientypen. Während Typ I und II den «Mainstream» dahingehend diffamieren, dass sie jener medialen und politischen Öffentlichkeit lügenhaftes und betrügerisches Handeln vorwerfen (und dies in einem stark abwertenden, teils auch beleidigenden Diskursstil), werden von Typ III zwar politische (aus subjektiver Sicht) Missstände der politischen Öffentlichkeit angesprochen, allerdings nicht in einem verleumdenden Stil. Vielmehr geht es darum, den eigenen Standpunkt klar zu machen und Alternativen aufzuzeigen, so z. B. Mosaik: «Wir zeigen solidarische Perspektiven zu tagespolitischen Themen und Alternativen zu autoritärer Wende und Rechtsrutsch auf.» ${ }^{94}$ Dabei wird gleichzeitig ein sachlicher Diskursstil angestrebt: «Nur wenn Alternativen seriös diskutiert werden, bleibt der politische Horizont offen und werden Standpunkte reflektiert» (Kontrast ${ }^{95}$ ).

Die politische Gesinnung wird bei diesem Alternativmedientyp am offensichtlichsten. Dies kann nicht nur implizit interpretiert werden, sondern auch basierend auf manifesten Inhalten, in denen Ursprünge in sozialdemokratischen Parteien (z. B. Kontrast) oder politisch links orientierten, auch marxistischen Bewegungen (z. B. Konkret, Rote Anneliese, Unsere Zeit, Der Funke) ausgeführt werden. Ebendies spiegelt sich nicht nur im Text wider, sondern auch in der optischen Gestaltung der Nachrichtenmedien. So wählen Nachrichtenmedien dieses Typs ein vorwiegend rotes Farbschema, wie in den drei beispielhaften Darstellungen aus den drei Untersuchungsländern in den folgenden Abbildungen 12, 13 und 14 deutlich wird (Der Funke, Rote Anneliese, Rote Fahne). Die Farbe Rot wird typischerweise für sozialdemokratische Parteien respektive Arbeiterparteien symbolisch eingesetzt. Ebenso ist eine rote Fahne als identifikatorisch für sozialistische und kommunistische Bewegungen zu betrachten. Die farbliche Auffälligkeit erweist

91 https://mosaik-blog.at/selbstverstaendnis/ (Stand: 11.03.2020)

92 https://derfunke.at/about/programm (Stand: 11.03.2020)

$93 \mathrm{https://kontrast.at/ueber-kontrast/(Stand:} \mathrm{11.03.2020)}$

94 https://mosaik-blog.at/selbstverstaendnis/ (Stand: 11.03.2020)

95 https://kontrast.at/ueber-kontrast/ (Stand: 11.03.2020) 
sich als idealtypisch für diesen Alternativmedientyp, wenngleich (wie bei jeder typologischen Unterscheidung) Ausnahmen existieren, wie am Beispiel von Kontrast zu sehen, das zwar laut Selbstbeschreibung auch sozialdemokratischen Ursprung ist ${ }^{96}$, sich allerdings in einem farblich (neutral) gelben Layout präsentiert, wodurch die Parteinähe nicht unbedingt auf den ersten Blick deutlich wird.

Abbildung 12: Layout der Website «Der Funke» ${ }^{97}$ (Österreich)

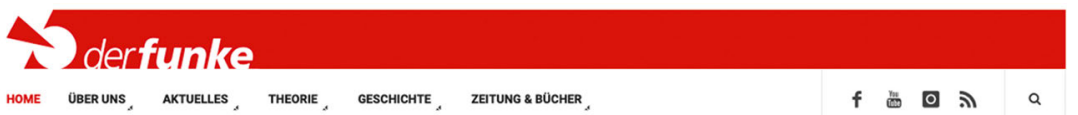

Abbildung 13: Layout der Website «Rote Anneliese»" ${ }^{98}$ (Schweiz)

f $\%$ in $8^{+}$要

Abbildung 14: Layout der Website «Rote Fahne News»" (Deutschland)

Rote Fahne News

Abgesehen von den farblichen Auffälligkeiten präsentieren sich die Nachrichtenseiten dieses Typs III sehr ähnlich wie die etablierten, professionellen Nachrichtenwebsites. Unter den jeweiligen Logos der Nachrichtenseiten finden sich (ähnlich wie bei Typ I) thematische Unterkategorien, die häufig nachrichtentypische Ressorts abbilden (z. B. «Politik», «Wirtschaft», «Internationales», wie beispielsweise bei Rote Fahne News, Kontrast oder Unsere Zeit zu sehen). Ebenso gibt es Social-Media-Verlinkungen am Kopf der Websites, während am unteren Ende Hinweise auf das Impressum und AGB gegeben werden. Aus visueller Sicht treten Nachrichtenmedien dieses Typs entsprechend professionell auf und äussern durch ihr Layout keine antizipierte Alternative.

96 In diesem Fall sogar produziert von Akteur_innen des SPÖ-Parlamentsklubs: https://kontrast. at/ueber-kontrast/ (Stand: 11.03.2020)

97 Screenshot von https://derfunke.at (Stand: 14.03.2019)

98 Screenshot von http://www.roteanneliese.ch (Stand: 14.03.2019)

99 Screenshot von https://www.rf-news.de (Stand: 14.03.2019) 


\section{Soziale Strukturen}

Die sozialen Strukturen, also die zu Wort kommenden Akteur_innen in Form von (Pseudo-)Journalist_innen und das antizipierte Publikum, unterscheiden sich klar von den ersten beiden Typen. Dabei ist die Seite der Produzierenden besonders divers: Neben Bürgerjournalist_innen (wonach jede_r mitmachen kann) finden sich unter den Autor_innen auch Expert_innen aus unterschiedlichen Bereichen. Bei Mosaik und Kontrast wird beispielsweise auf deren wissenschaftliche Expertise aus den unterschiedlichsten Bereichen hingewiesen. Weiter sind im empirischen Material Indizien dafür vorhanden, dass viele Produzierende aus zivilgesellschaftlichen Organisationen, politischen Parteien oder sozialen Bewegungen stammen (z. B. Mosaik, Unsere Zeit). Dies zeigt nochmals eindrücklich, wie ähnlich die Strukturen dieses Alternativmedientyps jenen der Alternativpresse der neuen sozialen Bewegungen aus den 1960er- und 1970er-Jahren sind.

Das angesprochene Publikum lässt sich implizit aus den Selbstbeschreibungen herauslesen. Die Medien richten sich an die Zivilgesellschaft, für die sie schliesslich eine Stimme einzunehmen versuchen. Es geht weniger darum, die Leserschaft von bestimmten Meinungen zu überzeugen (wie bei Typ I und II der Fall), als eine gleichgesinnte Gemeinschaft anzusprechen. Dabei wird vor allem das Wir-Gefühl oder das Gefühl einer Community stark gemacht, im Sinne einer Mobilisierung der Zivilgesellschaft, gegen gesellschaftliche Ungleichheiten und Missstände gemeinsam aufzustehen.

\section{Ökonomische Strukturen}

Auch aus ökonomischer Sicht ergibt sich bei diesem Medientyp ein vielfältiges Bild. Entgegen der Annahme, dass diese «klassische» Form alternativer Nachrichtenmedien (verweisend auf die Alternativpresse der zweiten Hälfte des 20. Jahrhunderts) nichtkommerziell agiert, konnten auch hier gegenteilige Befunde festgestellt werden: Zumindest Spenden scheinen eine bedeutsame Basis für diesen Alternativmedientyp darzustellen. Auf nahezu allen Newswebsites, die diesem Typ zugeordnet wurden, konnten Spendenaufrufe identifiziert werden, die - wie auch bei anderen Alternativ- und professionellen Medientypen - typischerweise mit einem Button auf der Website gekennzeichnet sind (z. B. Mosaik, Kontrast). So macht beispielsweise Mosaik transparent: «Der Großteil der Redaktionsarbeit wird ehrenamtlich geleistet, wir können daher auch keine Honorare für Artikel anbieten. Die Kosten für Blog, Technik, Materialien und anderes decken wir durch Mitgliedsbeiträge und Spenden ab. . ${ }^{100}$ 
Weiter finanzieren sich einige Medien über kostenpflichtige Abonnements (z. B. Der Funke, Rote Anneliese, Unsere Zeit), was überdies auf eine zunehmende Professionalisierung alternativer Nachrichtenmedien hinweist.

Insgesamt lässt sich Typ III dieser Typologie als Pendant zur Alternativpresse der neuen sozialen Bewegungen bezeichnen. Im Vergleich zu den ersten beiden Typen existieren wesentliche Unterschiede, die anhand der identifizierten Kernkategorien deutlich werden. Spätestens bei diesem Typ III zeigt sich zudem eindrücklich, weshalb eine typologische Unterscheidung alternativer Nachrichtenmedien im digitalen Zeitalter essentiell ist: Vor allem hinsichtlich der politischen Ausrichtung wird deutlich, dass alternative Nachrichtenmedien sehr unterschiedliche Sympathien verfolgen. Während Typ I beispielsweise in seinem Selbstverständnis und seiner Berichterstattung Hinweise darauf gibt, Politik des rechten politischen Flügels zu unterstützen und vor allem linksorientierte Politik abzuweisen, kann bei Typ III Gegenteiliges festgestellt werden. Typ III, der «Aufstand der Zivilgesellschaft», verdient seinen Namen vor allem dadurch, dass er die Stimme der Bevölkerung einnimmt und gegen soziale Ungleichheiten und gesellschaftliche Missstände einsteht. Medien dieses Typs kritisieren in erster Linie Rechtspopulismus, Kapitalismus oder die Ungleichbehandlung von Frauen und richten sich entsprechend gegen die herrschenden Eliten, die jene Missstände akzeptieren oder fördern würden. Diese sozialistische Ausrichtung zeigt sich auch in visueller und rhetorischer Hinsicht. Der im empirischen Material präsente rote Farbcode steht idealtypisch für sozialistische und kommunistische Bewegungen. Auch sprachlich stellt sich dieser Medientyp den Themen entsprechend mobilisierend dar, wodurch das Gemeinschaftsgefühl gestärkt wird. Dabei sind es neben Bürgerjournalist_innen durchaus auch Expert_innen unterschiedlicher Bereiche, die Inhalte erstellen. Die Beiträge können zum Teil kostenlos genutzt werden, teilweise stehen aber auch kostenpflichtige Abonnements zur Verfügung, was darauf hindeutet, dass sich auch dieser Alternativmedientyp zunehmend professionalisiert.

\section{VII.2.3.4 Typ IV: «Die seriöse Alternative»}

Abschliessend, aber nicht von minderer Wichtigkeit, wird an dieser Stelle Typ IV - «Die seriöse Alternative» - präsentiert. Auf den ersten Blick würden Nachrichtenmedien dieses Typs wohl nicht als «Alternativmedien» bezeichnet: Sie setzen sich vor allem für journalistische Qualität, beispielsweise in Form einer vertieften Rechercheleistung, ein und agieren folglich aus inhaltlicher wie auch aus Produzierendensicht professionell ${ }^{101}$. Die Alternative ergibt sich vor allem dahingehend, 
dass das kommerzialisierte Mediensystem abgelehnt wird, wonach primäres Ziel zu sein scheint, vertiefte Berichterstattung zur Verfügung zu stellen. Die Charakteristika dieses Typs IV werden nachfolgend kategorisch erläutert.

\section{Medieninhalte - Selbst- und Journalismusverständnis}

Medientyp IV steht laut Selbstbeschreibung für seriösen, fundierten Journalismus, der Hintergrundberichterstattung zu gesellschaftlich relevanten Themen biete. So flaggt beispielsweise die deutsche Website Krautreporter prominent auf der Startseite aus (vgl. Abbildung 17): «Verstehe die Zusammenhänge. Journalismus, dem du vertrauen kannst: Ein digitales Magazin, unabhängig und werbefrei, ermöglicht ausschließlich von tausenden Mitgliedern ${ }^{102}$. Ähnlich beschreibt sich auch das Online-Magazin Republik: «Die Republik ist ein digitales Magazin für Politik, Wirtschaft, Gesellschaft und Kultur. Finanziert von seinen Leserinnen und Lesern. Gemeinsam sind wir eine Rebellion gegen die Medienkonzerne, für die Medienvielfalt. Unabhängig, werbefrei - und mit nur einem Ziel: begeisternden Journalismus zu liefern ${ }^{103}$. Anhand der Zitate wird deutlich, dass journalistische Werte wie Vielfalt und Unabhängigkeit für diese Medien zentral sind, kommerzielle Medienkonzerne werden hingegen dezidiert abgelehnt. Somit ergibt sich auch die «Alternative» dieses Medientyps vorwiegend auf Basis der Kritik des kommerzialisierten Mediensystems und einer Kontrolle etablierter Medien insofern, als die Berichterstattungsqualität hinsichtlich gesellschaftlich relevanter Themen gewährleistet ist. Nachrichtenseiten des Typs IV dieser Typologie stehen vor allem für vertiefte Recherchen und Hintergrundberichterstattung ein, so beispielsweise Journal21:

Wir werden überflutet mit News und Kurznachrichten. Doch um die News zu verstehen, braucht es vertiefte Analysen, Kommentare und Hintergrundberichte. Da möchte www.journal21.ch einen Beitrag leisten. Ganz bewusst betreiben wir keinen reisserischen Journalismus. Wir richten uns an Leserinnen und Leser, die bereit sind, anspruchsvolle Texte zu konsumieren. Wir möchten fundierte Hintergrundberichte, Analysen und Kommentare bieten. ${ }^{104}$

In ähnlicher Weise postuliert die Newsseite Infosperber: «Das Fernsehen informiert vorwiegend über das, was Einschaltquoten bringt. Grosse Zeitungen leiden an sinkenden Inserateeinnahmen. Deshalb ködern sie Inserenten mit irreführender PR im redaktionellen Teil. Infosperber will diese grossen Informa-

102 https://krautreporter.de (Stand: 19.03.2020)

103 https://www.republik.ch/about (Stand: 19.03.2020)

104 https://www.journal21.ch/ueber-uns (19.03.2020) 
tions-Medien nicht konkurrenzieren, sondern sie ergänzen.» ${ }^{105}$ Das primäre Ziel dieses Medientyps besteht demnach nicht unbedingt darin, etablierte Medien als Opposition zu sehen, sondern vielmehr darin, diese durch vertiefte Recherchen und «fundierten Journalismus» zu ergänzen. Abgelehnt wird jedoch neben der Kommerzialisierung ein so bezeichneter «reisserischer Journalismus», also skandalisierende, polarisierende und aufmerksamkeitserregende Berichterstattung. Insofern nimmt Medientyp IV - wie auch die restlichen Alternativmedientypen - die Funktion einer «Vierten Gewalt» ein, zumal Kritik an etablierten Nachrichtenmedien durchaus verfolgt wird (so die Republik in ihrem Manifest: «Journalismus ist ein Kind der Aufklärung. Seine Aufgabe ist die Kritik der Macht. [Hervorhebung durch Verfasser]» ${ }^{106}$ ). Dies geschieht laut Selbstverständnis auf Basis journalistischer Standards und einer «besseren» Rechercheleistung im Vergleich zum kommerzialisierten Mediensystem:

Wir sind kritisch. [...] In unserer journalistischen Arbeit stellen wir diese Überzeugung der Gesellschaft entgegen: in Analysen, Kommentaren und aufwändigen Hintergrundrecherchen. Hierbei orientieren wir uns an der «Erklärung der Rechte und Pflichten der JournalistInnen» des Presserats sowie an den dazugehörigen Richtlinien. (Das Lamm ${ }^{107}$ )

Gleichbedeutend wird journalistische Qualität grossgeschrieben. Die Medien betonen die «Zeit für Qualität» ${ }^{108}$, wonach entgegen der Entwicklungen im Mediensystem erst Berichte veröffentlicht würden, wenn sie den Qualitätsansprüchen genügen, mit dem Ziel, eine «Faktenbasis für eine qualifizierte politische Debatte» ${ }^{109}$ wiederherzustellen.

\section{Medieninhalte - Themen}

Aus subjektiver Sicht der Nachrichtenmedien widmet sich die inhaltliche Schwerpunktsetzung dem "gesellschaftlich Relevanten», wobei davon auszugehen ist, dass hierbei aus einer demokratieorientierten Perspektive argumentiert wird, wie beispielsweise anhand der Republik deutlich wird: «Denn in der Demokratie gilt das Gleiche wie überall im Leben: Menschen brauchen vernünftige Informationen, um vernünftige Entscheidungen zu treffen. [Hervorhebung durch Verfasser]» ${ }^{110}$. Ein Fokus liegt auch Addendum zufolge auf «relevante[n] Themen, aus

\footnotetext{
105 https://www.infosperber.ch/Uber-uns (Stand 19.03.2020)

106 https://www.republik.ch/manifest (Stand: 20.03.2020)

107 https://daslamm.ch/das-ist-lamm (Stand: 20.03.2020)

108 https://krautreporter.de/mitglied_werden (Stand: 20.03.2020)

109 https://www.addendum.org/redaktionelle-richtlinien/(Stand: 20.03.2020)

110 https://www.republik.ch/manifest (Stand: 20.03.2020)
} 
den Bereichen Politik, Wirtschaft und Gesellschaft» ${ }^{111}$, mit dem Ziel, politische Zusammenhänge durch vertiefte Berichterstattung transparent zu machen (so auch die Unterschrift von Krautreporter: «Verstehe die Zusammenhänge» (vgl. Abb. 17), oder Infosperber: «Infosperber sieht, was andere übersehen» ${ }^{112}$ ). Alle Nachrichtenseiten dieses Typs setzen folglich einen Schwerpunkt auf Hintergrundberichterstattung, um Leser_innen mit Informationen zu versorgen, die in den Leitmedien untergehen. Es wird allerdings (nicht wie bei Typ I und II) der Eindruck erweckt, dass bestimmte Sachverhalte vom «Mainstream» verschwiegen werden, sondern dass aufgrund des Wandels des Mediensystems im Zuge der Kommerzialisierung journalistische Qualitätsstandards geringere Beachtung finden (z. B. aufgrund von Ressourcenmangel, aber auch mit dem Ziel der Aufmerksamkeitsgenerierung beim Publikum). Schon allein aufgrund der Ablehnung eines «reisserischen Journalismus» und angesichts des selbstauferlegten Qualitätsanspruchs finden Human Interest Stories keinen Einzug in die Berichterstattung dieses Medientyps. Vielmehr handelt es sich mehrheitlich um sehr umfangreiche Artikel (die dafür von geringerer Quantität im Vergleich zu klassischen Leitmedien sind), in denen unterschiedliche Meinungen unterschiedlicher Quellen aufgezeigt werden. Die Themen richten sich nach der Aktualität allgemein relevanter Sachverhalte (z. B. Klima, Digitalisierung ${ }^{113}$, Demokratie, Migration ${ }^{114}$, u. Ä.), häufig auch im Bereich des Investigativ-Journalismus. Die Medien beschreiben ihre Berichterstattung selbst als politisch neutral (z. B.: «Infosperber ist unabhängig von wirtschaftlichen, politischen und weltanschaulich-religiösen Interessen» $\left.{ }^{115}\right)$. Abgelehnt wird aber z. B. dezidiert (hier im Fall der Republik) der Aufstieg «autoritärer Politik $»^{116}$; ebenso vertreten die Medien dieses Typs eine klare Orientierung an demokratischen Werten.

\section{Medieninhalte - Rhetorik/Symbolik}

Aus sprachlicher, rhetorischer Sicht ähnelt Medientyp IV dem professionellen Journalismus, was mit den sozialen Strukturen, d. h. den agierenden (professionellen) Journalist_innen, zusammenhängt. Wie auch dem Selbstverständnis zu entnehmen ist, legen die Journalist_innen Wert auf Objektivität und Quellenvielfalt. Dementsprechend finden sich, wie beispielsweise bei Typ I und Typ II, keine negativ wertenden oder gar diffamierenden Beschreibungen des «Mainstreams», und ebenso wenig lässt sich eine Kampfrhetorik wie bei Typ III feststellen. Ent-

\footnotetext{
111 https://www.addendum.org/redaktionelle-richtlinien/ (Stand: 20.03.2020)

112 https://www.infosperber.ch/Uber-uns (Stand: 23.03.2020)

113 https://www.republik.ch (Stand: 23.03.2020)

$114 \mathrm{https}: / /$ daslamm.ch/format/gesellschaft-und-politik/ (Stand: 23.03.2020)

115 https://www.infosperber.ch/Uber-uns (Stand: 23.03.2020)

116 https://www.republik.ch (Stand: 23.03.2020)
} 
sprechend der anvisierten Zielgruppe kann der Diskursstil als intellektuell und sachlich beschrieben werden.

Typ IV versucht nicht nur über Sprache bzw. Diskurstil und der entsprechenden Berichterstattung, ein seriöses Bild zu hinterlassen, sondern auch über das optische Erscheinungsbild. In den folgenden Abbildungen 15, 16 und 17 werden Beispiele aus den drei Untersuchungsländern demonstriert. Allen gemein ist ein vorwiegend schlichtes Design, vor allem was die Schriftzüge der Medientitel angeht, die mehrheitlich in Grautönen (Republik ${ }^{117}$, Krautreporter ${ }^{118}$ ) oder zumindest gedämpften Farben (Addendum ${ }^{119}$ ) dargestellt sind. Auf Logos in Form von Symbolen wird verzichtet, wodurch insgesamt ein cleaner Eindruck vermittelt wird. Dabei zeigen sich gerade die hier demonstrierten Websites in einer modernen Weise (im Sinne von «Weniger ist mehr»). Die Newssites folgen in diesem Fall nicht dem gewohnten News-Layout einer kategorischen Darstellung von Themenrubriken, sondern werden erst durch einen Klick auf einen kleinen Button angezeigt. Viele Inhalte können zudem durch Scrollen der Hauptseite angesteuert werden. Dies ist allerdings nicht bei allen Seiten dieses Medientyps der Fall, Seiten wie Infosperber $^{120}$ oder Das Lamm ${ }^{121}$ folgen beispielsweise noch dem klassischen Layout.

\section{Abbildung 15: Layout der Website «Addendum» ${ }^{122}$ (Österreich)}

addendum

das, was fehlt
Kontakt | Allgemeine Nutzungsbedingungen I Datenschutz | Imp - 2017 Quo Vadis Veritas R

Bereits die Titel der hier beschriebenen Online-Nachrichtenmedien geben Aufschluss über deren Selbstbild. Offensichtlich wird dies beispielsweise bei der österreichischen Website Addendum, aus dem Lateinischen übersetzt «das Hinzuzufügende», die den Untertitel «das, was fehlt» trägt. Die Phrase bezieht sich relational auf die Berichterstattung etablierter Massenmedien, wonach davon ausgegangen wird, dass es dort an bestimmten Informationen mangelt. Verfolgt wird demnach - wie bereits erläutert - eine vertiefte Hintergrundberichterstattung.

117 https://www.republik.ch (Stand: 19.03.2020)

118 https://krautreporter.de/mitglied_werden (Stand: 19.03.2020)

119 https://www.addendum.org (Stand: 19.03.2020)

120 https://www.infosperber.ch (Stand: 19.03.2020)

121 https://daslamm.ch (Stand: 19.03.2020)

122 Screenshot von https://www.addendum.org (Stand: 14.03.2019) 
Abbildung 16: Layout der Website «Republik» ${ }^{123}$ (Schweiz)

Unabhängiger Journalismus ohne Bullshit: Willkommen bei der Republik.

Auch der Titel der Schweizer Website Republik kann von der lateinischen Bedeutung von «res publica», also der «öffentlichen Angelegenheit», hergeleitet werden. Schliesslich widmet sich das Magazin relevanten Sachverhalten, die die Öffentlichkeit betreffen.

Abbildung 17: Layout der Website «Krautreporter» ${ }^{124}$ (Deutschland)

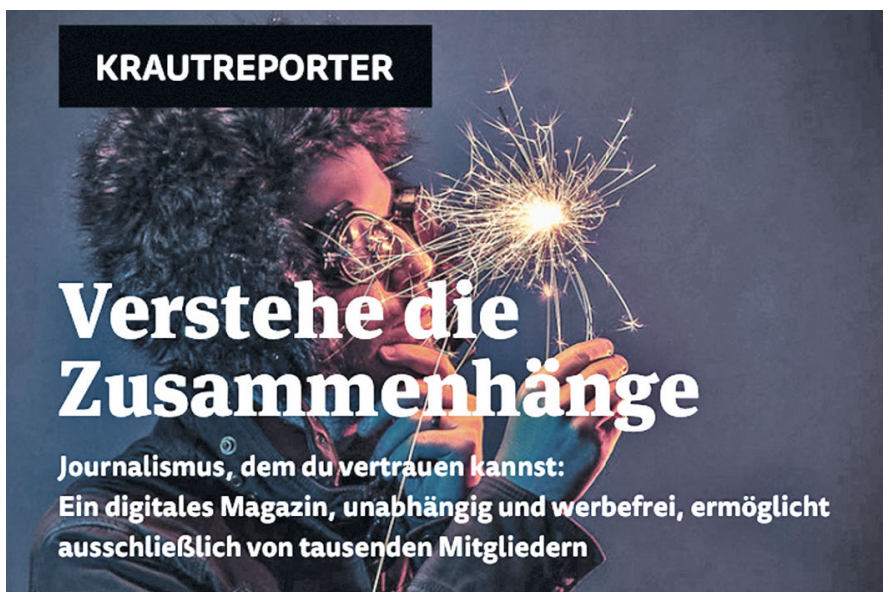

Die Bezeichnung «Krautreporter» beispielsweise kann von dem englischen Begriff des «grassroot journalism» hergeleitet werden. Die Begrifflichkeit steht synonym für partizipativen Bürger_innenjournalismus, «grassroot» (dt.: Graswurzel) bedeutet in diesem Kontext Journalismus «von unten», also von der Zivilgesellschaft. «Kraut» könnte an dieser Stelle eine ähnliche Bedeutung einnehmen. Die hier illustrierten Seiten erscheinen als idealtypisch für «Die seriöse Alternative». Sie verfolgen einerseits das Ziel, rhetorisch und visuell seriös zu erscheinen, erwecken aber gleichzeitig den Eindruck eines modernen, digitalaffinen Startups, das versucht, Journalismus in einer neuen Art zu bieten.

123 Screenshot von https://www.republik.ch (Stand: 14.03.2019)

124 Screenshot von https://krautreporter.de/ (Stand: 14.03.2019) 


\section{Soziale Strukturen}

Wie bereits angedeutet, ist die Produzierendenseite diese Medientyps professionell ausgestattet, das heisst mit professionellem Journalismus vergleichbar. Medien dieses Typs verweisen auf eine Redaktion und dort agierende Personen in unterschiedlichen Funktionen, wie beispielsweise Chefredaktion, Fotoredaktion, Design etc. Die Produzierendenseite ist demzufolge stark ausdifferenziert. Innerhalb eigener Bereiche auf den Websites (meist in der Rubrik «Team») werden detaillierte Informationen zu den dort tätigen Mitarbeitenden respektive Journalist_innen gegeben. Dies erfolgt zum Teil personalisiert, indem Portraits der dort Tätigen angeführt werden, mit Foto und Kurzbeschreibung, z. B. in Form von Selbstbeschreibungen wie bei Krautreporter ${ }^{125}$ oder auch anhand eines Imagefilms wie bei Das Lamm² ${ }^{126}$. Die Beschreibungen der Autor_innen bestätigen den professionellen Gesamteindruck der Nachrichtenmedien. Wie an den (häufig vorhandenen) Kurzbiographien ablesbar, verfügt eine Vielzahl der Journalist_innen über journalistische Ausbildungen und/oder Hochschulabschlüsse; zum Teil verweisen sie zudem explizit auf bisherige berufliche Tätigkeiten im professionellen Journalismus.

Das antizipierte Publikum, d. h. die Leser_innen, soll dem Selbstverständnis der Medien folgend einen Bedarf an kritischer Hintergrundberichterstattung besitzen und zusätzliche Informationen verlangen, um gesellschaftliche Zusammenhänge zu verstehen. Die Leser_innen werden dabei zum Teil als «Verleger_innen» (z. B. Republik) oder Mitglieder (z. B. Krautreporter, Addendum) bezeichnet, was gleichzeitig auf die Unabhängigkeit der Medien (so können sie beispielsweise auch (kostenpflichtig) eine Genossen-Funktion des Mediums Krautreporter einnehmen und dann bei der Unternehmensstrategie mitentscheiden ${ }^{127}$ ) und den wesentlichen Stellenwert der Lesenden selbst hindeuten soll. Im Generellen wird der Gedanke einer Gemeinschaft von Medienschaffenden und Lesenden in diesem Typ stark gemacht, was auch zum Konzept des Crowdfundings passt. Dadurch wird der Eindruck erweckt, ein gemeinsames Interesse in Form von fundiertem, gut recherchiertem Journalismus zu verfolgen. Das Publikum selbst erscheint (ebenso wie die Produzierenden) kritisch gegenüber dem klassischen, kommerzialisierten Mediensystem, wie auch in Abbildung 18 ersichtlich wird, die eines von vielen Leser_innenzitaten präsentiert, die auf der Website der Republik abgebildet und mit Videos der Lesenden gestützt werden. Das antizipierte Publikum kann sehr wohl als «intellektuell» oder zumindest als überdurchschnittlich interessiert an gesellschaftlichen Zusammenhängen beschrieben werden, so schreibt beispielsweise Journal21 dezidiert: «Wir richten uns an Leserinnen und Leser, die

125 https://krautreporter.de/team (Stand: 29.03.2020)

126 https://daslamm.ch/das-ist-lamm (Stand: 29.03.2020)

127 http://genossenschaft.krautreporter.de (Stand: 29.03.2020) 
bereit sind, anspruchsvolle Texte zu konsumieren ${ }^{128}$. Inforsperber richtet sich ausdrücklich an «interessierte Bürgerinnen und Bürger» ${ }^{129}$. Auch implizit zeigt sich diese Ausrichtung, zumal die veröffentlichten Texte in der Regel von grossem Umfang sind und anspruchsvolle Themen aus Politik, Wirtschaft, Gesellschaft umreissen.

Abbildung 18: Leserinnenquote der «Republik» ${ }^{130}$

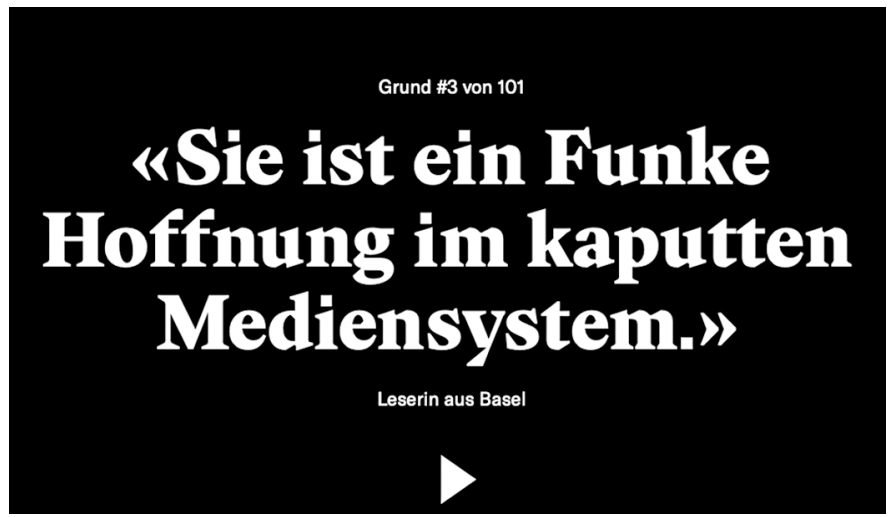

\section{Ökonomische Strukturen}

Die in diesem Falltyp beschriebenen Nachrichtenmedien arbeiten vorwiegend ökonomisch und demnach professionell im Sinne einer Orientierung am professionellen Informationsjournalismus. Neben Spendenaufrufen, die auch für die anderen Typen alternativer Nachrichtenmedien kennzeichnend sind, werden Inhalte und Abonnements kostenpflichtig angeboten. Kennzeichnend für diesen Typ ist, dass häufig über Crowdfunding Aufrufe zur finanziellen Unterstützung geschaltet werden (z. B. Republik, Krautreporter, Addendum). Crowdfunding stellt eine moderne Form der Projektfinanzierung dar, bei der Nutzer_innen finanzielle Beiträge leisten und dadurch teilweise auch direkt von dem Projekt profitieren können, wie in diesem Fall durch die Nutzung der Nachrichtenbeiträge. Ein wesentlicher Unterschied zum blossen Spendenaufruf besteht somit darin, dass durch das Crowdfunding ein Gemeinschaftsgefühl hergestellt wird, im Sinne einer Mitgliedschaft und des Erstrebens eines gemeinsamen Ziels (hier: fundierter Journalismus).

\footnotetext{
128 https://www.journal21.ch/ueber-uns (Stand: 29.03.2020)

129 https://www.infosperber.ch/Uber-uns (Stand: 30.03.2020)

130 Screenshot von https://www.republik.ch (Stand: 14.03.2019)
} 
Zusammenfassend sticht Typ IV «Die seriöse Alternative» vor allem deswegen aus dieser Typologie heraus, da er auf den ersten Blick und aus einer normativen Sichtweise vermutlich nicht ad hoc als Alternativmedium eingeordnet würde. Schliesslich wird «der Mainstream» aus Politik und Medien nicht wie bei den anderen Typen dezidiert abgelehnt, im Sinne einer Ablehnung der «öffentlichen» oder hegemonialen Meinung bzw. Berichterstattung. Vielmehr ergibt sich die «Alternative» aus der Ablehnung der Kommerzialisierung des Mediensystems im Generellen, wonach die Opposition dadurch entsteht, dass Typ IV für eine fundierte, gut recherchierte Berichterstattung einsteht, um gesellschaftliche $\mathrm{Zu}$ sammenhänge besser aufzuzeigen. Der thematische Fokus liegt demnach auf relevanten Themen aus Politik, Wirtschaft und Gesellschaft. Die Berichterstattung ist sachlich; ebenso wird visuell ein seriöser Eindruck erweckt. Unter den Produzierenden finden sich mehrheitlich ausgebildete Journalist_innen, wobei ein kritisches, interessiertes Publikum angesprochen wird. Nicht nur aus Produzierendenperspektive agieren Medien dieses Typs sehr professionell, sondern auch aus ökonomischer Sicht. Typ IV finanziert sich häufig über Crowdfunding und/oder bietet kostenpflichtige Abonnements an.

\section{VII.2.4 Zusammenfassung: Typologie alternativer Nachrichtenmedien}

In diesem Unterkapitel werden abschliessend die wesentlichen Eckpunkte der typologischen Unterscheidung von alternativen Nachrichtenmedien zusammengefasst, um deren Gemeinsamkeiten und Unterschiede anhand von Gegenüberstellungen deutlich zu machen. Dabei soll nochmals aufgezeigt werden, worin sich alle alternativen Nachrichtenmedien im deutschsprachigen Raum ähneln: Sie beschreiben sich selbst als Vierte Gewalt gegenüber der medialen und politischen hegemonialen Öffentlichkeit, wonach sie versuchen, eine Korrektivfunktion dahingehend einzunehmen, mediale und/oder politische Eliten erstens zu kontrollieren und zweitens zu kritisieren. Folgende Definition (basierend auf dem Selbstverständnis) alternativer Nachrichtenmedien kann hierfür formuliert werden:

Alternative Nachrichtenmedien im deutschsprachigen Raum positionieren sich selbst als «Vierte Gewalt», indem sie die hegemoniale Politik und/oder Medien kritisieren und kontrollieren. Sie nehmen entweder eine ergänzende Funktion gegenüber etablierten Medien ein (z. B. in Form vertiefter Recherchen) und sehen sich dahingehend selbst als Alternative zum kommerzialisierten Mediensystem. Oder aber sie beschreiben sich selbst (vor allem inhaltlich) als klare Opposition zum so bezeichneten «Mainstream», also der medialen und politischen Öffentlichkeit dies aber in sehr unterschiedlicher Ausprägung, je nach Alternativmedientyp. 
Diese unterschiedlichen Ausprägungen zeigten sich im Rahmen der induktiv geleiteten qualitativen Analyse des empirischen Materials und können anhand von vier kontrastierenden Falltypen näher beschrieben werden. In diesem Kontext kann eine Unterscheidung dahingehend vorgenommen werden, dass (1) sich die antizipierte Position einer «Vierten Gewalt» in unterschiedlichen Dimensionen je nach Typ äussert, (2) die sozialen wie auch ökonomischen Strukturen variieren und (3) die inhaltliche Ebene der Medien verschieden ausgeprägt ist. In der Folge werden Gemeinsamkeiten und Unterschiede der vier Typen alternativer Nachrichtenmedien gegenübergestellt:

\section{(1) Die "Vierte Gewalt"}

Die selbstbeschriebene «Alternative» der analysierten Nachrichtenmedien entsteht bei allen Typen gleichermassen dadurch, dass gewisse Aspekte der medialen und politischen Öffentlichkeit kritisiert werden. Demokratietheoretisch höchst relevant ergibt sich dadurch die Selbstpositionierung einer «Vierten Gewalt», zumal mediale und politische Eliten einerseits kritisiert und andererseits kontrolliert werden, wonach die - für die öffentliche Kommunikation unabdingbare - Kritik- und Kontrollfunktion gegeben ist. Würde von einer normativen Betrachtung der untersuchten Nachrichtenmedien Abstand genommen und stattdessen auf deren Selbstbeschreibung fokussiert, würden dadurch demokratische Ansprüche erfüllt. Relevant ist eine Unterscheidung dahingehend, wie sich die Selbstpositionierung als Opposition zum «Mainstream» konkret ausgestaltet, zumal unter den vier Typen starke Kontraste identifiziert werden konnten.

Typ I, der «Aufdecker der Mainstreamlügen», streicht die Alternative vor allem dadurch heraus, dass die Berichterstattung etablierter Medien wie auch politische Eliten selbst als lügenhaft charakterisiert werden, und erhebt den Anspruch, ebendiese Lügen («Fake News») aufzudecken und wahrheitsgemässe Berichterstattung zur Verfügung zu stellen. Die hegemoniale Öffentlichkeit aus Politik und Medien wird entsprechend abgewertet und diffamiert, wodurch die Opposition besonders deutlich wird. Typ II, «Verschwörung und Spiritualität», kritisiert in ähnlicher Weise herrschende Politik und etablierte Medien und geht von einer grösseren Verschwörung von Eliten aus, die im Hintergrund die Fäden ziehen und einen geheimen Plan verfolgen. Die Alternative ergibt sich einerseits dadurch, dass sich Nachrichtenmedien dieses Typs die Aufgabe stellen, Eliten zu kontrollieren, angebliche Geheimnisse zu lüften und über die «absolute Wahrheit zu berichten». Andererseits wird bereits durch die visuelle Gestaltung einschlägiger Medien eine Alternative zum etablierten Journalismus deutlich, indem auf gängige visuelle Darstellungsformen verzichtet wird und konspirative Züge ebenso durch düstere Erscheinungsbilder und einschlägige Symboliken deutlich werden. Typ III, «Aufstand der Zivilgesellschaft», sieht sich als Opposition gegenüber der herrschenden Politik und kritisiert aus einer politisch linksorientierten 
Haltung gesellschaftspolitische Probleme wie soziale Ungleichheit, Kapitalismus oder Rechtspopulismus und sieht sich dementsprechend als Stimme der Zivilgesellschaft. Typ IV, «Die seriöse Alternative», ist kritisch gegenüber einer Kommerzialisierung des Mediensystems eingestellt. Sie sieht darin eine Abkehr relevanter Berichterstattung und bietet eine Alternative dadurch, dass sie den Lesenden vertiefte Recherchen liefert.

\section{(2) Soziale und ökonomische Strukturen}

Hinsichtlich der sozialen und ökonomischen Strukturen wurde anhand der typologischen Unterscheidung deutlich, dass vor allem in Bezug auf eine Professionalisierung alternativer Nachrichtenmedien starke Kontraste vorhanden sind. Entgegen der Annahme, die vor allem im bisherigen Stand der Forschung stark gemacht wurde, dass alternative Nachrichtenmedien nicht professionell agieren, konnte anhand des empirischen Materials Gegenteiliges festgestellt werden. Die nachfolgende Abbildung 19 veranschaulicht die Einordnung der vier identifizierten Typen auf zwei Achsen: Erstens wird der Ökonomisierungsgrad dargestellt, der angibt, inwieweit die einzelnen Alternativmedientypen ökonomisch agieren, also auf Profit ausgerichtet sind.

Abbildung 19: Soziale und ökonomische Strukturen alternativer Nachrichtenmedien (Eigene Darstellung)

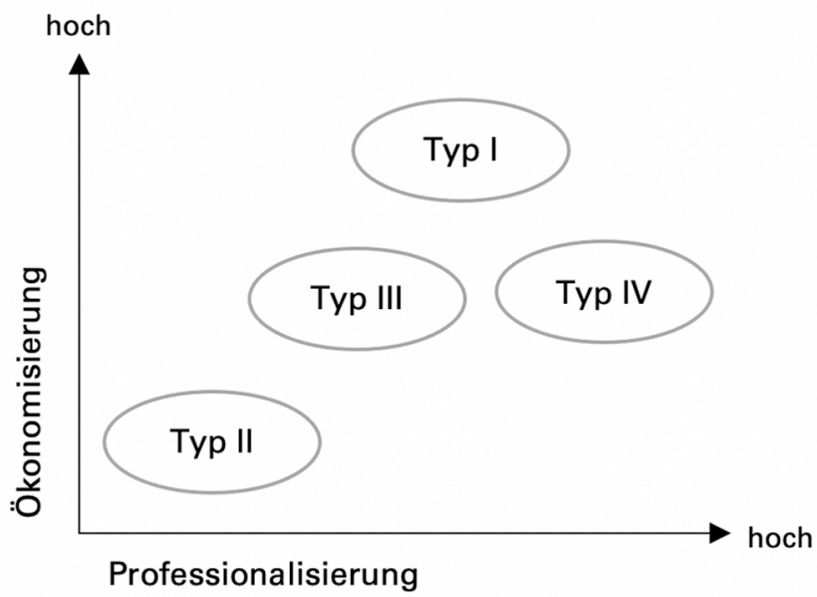

Zweitens ist der Professionalisierungsgrad abgebildet, der die sozialen Strukturen mit Fokus auf die Produzierendenseite angibt. Je stärker sich alternative Nachrichtenmedien an klassischen Strukturen im Sinne ausgebildeter Journalist_innen und redaktioneller Leitungen orientieren, umso höher ist dieser Grad. 
Wie in Abbildung 19 dargestellt, zeichnet sich vor allem Typ I («Aufdecker der Mainstreamlügen») durch einen hohen Ökonomisierungsgrad aus. Medien dieses Typs arbeiten tendenziell ökonomisch bzw. sind kommerziell ausgerichtet, indem sie kostenpflichtige Abonnements anbieten oder Werbung in ihre Online-Auftritte integrieren. Nicht nur in dieser Hinsicht und bezüglich der Darstellungsform agiert Typ I professionell, sondern auch hinsichtlich der sozialen Strukturen. Häufig schreiben professionelle Journalist_innen für einschlägige Nachrichtenseiten, die redaktionell hierarchisch aufgebaut sind. Teilweise agieren aber durchaus auch laienhafte Akteur_innen, weshalb der Professionalisierungsgrad in dem Graph mittig positioniert ist. Obwohl sich Typ I und Typ II («Verschwörung und Spiritualität») häufig inhaltlich überschneiden ${ }^{131}$, zeigen sich hinsichtlich der sozialen und ökonomischen Strukturen deutliche Unterschiede, wonach Typ II in beiden Ausprägungen laienhaft agiert, also allenfalls (zumindest laut Selbstbeschreibung) über Spendenaufrufe finanzielle Mittel erwirbt und die Produzierendenseite aus Laienjournalist_innen besteht. Während Typ III («Aufstand der Zivilgesellschaft») im Graphen mittig platziert ist, vergleichsweise semi-professionell agiert, neben Lai_innen auch Verteter_innen aus NGOs auf der Produzierendenseite vertreten sind und sich dieser Typ vorwiegend über Spendenaufrufe und teils über Abonnements finanzielle Ressourcen verschafft, weist Typ IV ( seriöse Alternative») den vergleichsweise höchsten Professionalisierungsgrad auf. Dies resultiert daraus, dass hauptsächlich ausgebildete Journalist_innen mit redaktioneller Leitung einschlägige Nachrichtenmedien bewirtschaften. Diese weisen zudem einen relativ hohen Ökonomisierungsgrad auf, da sie sich mehrheitlich (häufig über Crowdfunding) ihre finanziellen Mittel beschaffen.

\section{(3) Medieninhalte}

Die Medieninhalte offenbaren weitere wesentliche Unterschiede zwischen den vier Typen. Dabei ergeben sich das Selbstverständnis wie auch das journalistische Verständnis der Nachrichtenmedien sowohl aus den Themen, die inhaltlich aufbereitet werden, als auch dezidiert über Inhalte auf den Websites, in denen eine explizite Selbstbeschreibung erfolgt. Weiter äussern sich die Medieninhalte über die Berichterstattung verschiedener Themenfelder, etwa über die Rhetorik (oder den Diskursstil) und die visuelle Ausgestaltung der Websites (Layout). Tabelle 4 veranschaulicht die zentralen Unterschiede zwischen den vier Alternativmedientypen und gibt die wesentlichen Merkmale je Kategorie wieder.

131 Insofern können im empirischen Wirklichkeitsausschnitt auch Mischtypen identifiziert werden. Die typologische Darstellung erfolgt demnach idealtypisch. 
Tabelle 4: Medieninhalte alternativer Nachrichtenmedien nach Medientyp

\begin{tabular}{|c|c|c|c|c|}
\hline & $\begin{array}{l}\text { Typ I: } \\
\text { Aufdecker } \\
\text { der Mainstream- } \\
\text { lügen } \\
\end{array}$ & $\begin{array}{l}\text { Typ Il: } \\
\text { Verschwörung } \\
\text { und Spiritualität }\end{array}$ & $\begin{array}{l}\text { Typ III: } \\
\text { Aufstand der } \\
\text { Zivilgesellschaft }\end{array}$ & $\begin{array}{l}\text { Typ IV: } \\
\text { Die seriöse } \\
\text { Alternative }\end{array}$ \\
\hline $\begin{array}{l}\text { Selbst- und Journa- } \\
\text { lismusverständnis }\end{array}$ & $\begin{array}{l}\text { Media-Watchdogs, } \\
\text { Unabhängigkeit, } \\
\text { Meinungsfreiheit, } \\
\text { unzensiert }\end{array}$ & $\begin{array}{l}\text { Weltverbesserer, } \\
\text { Geheimnislüfter }\end{array}$ & $\begin{array}{l}\text { Stimme der } \\
\text { Zivilgesellschaft, } \\
\text { kämpferisch gegen } \\
\text { Eliten }\end{array}$ & $\begin{array}{l}\text { Fundierter, } \\
\text { unabhängiger und } \\
\text { relevanter Jour- } \\
\text { nalismus, gegen } \\
\text { «reisserischen» } \\
\text { Journalismus }\end{array}$ \\
\hline Themen & $\begin{array}{l}\text { Kritik an Medien und } \\
\text { Politik, «Fake News» } \\
\text { (des Mainstreams), } \\
\text { Migrationskritik, } \\
\text { Genderkritik }\end{array}$ & $\begin{array}{l}\text { Esoterik, } \\
\text { Spirituelles, } \\
\text { Elitenver- } \\
\text { schwörung }\end{array}$ & $\begin{array}{l}\text { Kapitalismuskritik, } \\
\text { Kritik an den } \\
\text { herrschenden Eliten, } \\
\text { Soziale Gerechtig- } \\
\text { keit }\end{array}$ & $\begin{array}{l}\text { Gesellschaftlich } \\
\text { relevante Themen } \\
\text { aus Politik, Wirt- } \\
\text { schaft, Gesellschaft }\end{array}$ \\
\hline Rhetorik/ Symbolik & $\begin{array}{l}\text { Ironisch, zynisch, } \\
\text { Layout teils hoch } \\
\text { professionalisiert }\end{array}$ & $\begin{array}{l}\text { Dunkles, düsteres } \\
\text { Erscheinungs- } \\
\text { bild, Weltunter- } \\
\text { gangs-Symbolik }\end{array}$ & Mobilisierend & $\begin{array}{l}\text { Seriöses Erschei- } \\
\text { nungsbild, schlicht, } \\
\text { intellektuell }\end{array}$ \\
\hline
\end{tabular}

Hervorzuheben ist hierbei nochmals die im empirischen Material identifizierte starke Präsenz von alternativen Nachrichtenmedien, die Typ I zugeordnet werden können. Dieser Typ ist laut Selbstbeschreibung dadurch gekennzeichnet, eine antizipierte Media-Watchdog-Funktion zu erfüllen und gleichbedeutend Kritik an hegemonialen Medien und (häufig linksorientierter) Politik zu äussern, indem versucht wird, in einer rhetorisch zynischen Art und Weise deren Lügen (oder «Fake News») aufzudecken. Davon zu unterscheiden ist Typ II, der zwar in ähnlicher Weise Lügen des «Mainstreams» thematisiert, bei dem diese aber im Kontext einer grösseren Elitenverschwörung interpretiert werden, was sich auch visuell in z. B. einem düsteren Layout niederschlägt. Medien dieses Typs sehen sich entsprechend als Lüfter der «absoluten Wahrheit». Typ III ist wiederum von den anderen Typen abzugrenzen, da er am stärksten versucht, eine Stimme der Zivilgesellschaft einzunehmen, wie es auch bei den neuen sozialen Bewegungen der 1960er- und 1970er-Jahre der Fall war. Dabei agieren die Medien stark mobilisierend und setzen sich für soziale Gerechtigkeit ein. Auch Typ IV weist starke Kontraste zu den ersten drei Typen auf, indem er sich vorwiegend gegen kommerzialisierte Massenmedien richtet und für relevante Berichterstattung einsteht. Typ IV richtet sich an traditionell journalistische Normen und Werte und präsentiert sein seriöses Auftreten auch in visueller Hinsicht. 
Die typologische Unterscheidung der insgesamt vier Typen, die induktiv aus dem empirischen Material und basierend auf einer theoretischen Sättigung resultierten, ist aus mehreren Gründen von hoher Relevanz - nicht nur für die empirische Erforschung alternativer Nachrichtenmedien, sondern auch aus einer gesellschaftlichen Perspektive. Erstens zeigte sich - vor allem aufgrund der Erhebung vielfältiger Nachrichtenmedien, die der Grunddefinition alternativer Nachrichtenmedien, nämlich der antizipierten Positionierung einer «Alternative zu medialen und/oder politischen Eliten», entsprachen, - dass alternative Nachrichtenmedien in vielfältiger Form auftreten können. Dies entspricht der Annahme einer digitalen Transformation insofern, als ein disperser Pool an öffentlichen Kommunikator_innen existiert. Dahingehend ist besonders hervorzuheben, dass alternative Nachrichtenmedien nicht ausschliesslich im rechtspopulistischen oder desinformativen Spektrum ${ }^{132}$ zu verorten sind, wie es der aktuelle Stand der Forschung vermuten lässt. Zweitens wurde deutlich, dass alternative Nachrichtenmedien zumindest zum Teil und verglichen mit etablierten Nachrichtenmedien durchaus hoch professionalisiert sind, wodurch die Annahme einer nichthierarchischen und nichtkommerziellen Charakteristik von Alternativmedien nicht mehr haltbar ist, wie es bei früheren Definitionen der Fall war (z. B. Atton, 2011). Drittens kann aus einer normativen, demokratietheoretischen Sicht nicht angenommen werden, dass alternative Nachrichtenmedien per se dysfunktional für die öffentliche Kommunikation sind, da vor allem Typ IV journalistische Standards nicht nur einhält, sondern darüber hinaus versucht, diese in besonders ausgeprägtem Masse zu verwirklichen. Dies beispielsweise durch vertiefte Recherchen gesellschaftlich relevanter Themen aus Politik und Wirtschaft. Auch bei Typ III richtet sich die Kritik gegenüber politischen Eliten zum Wohle sozialer Gerechtigkeit, mit einer starken Bürger_innenorientierung und ohne einen diffamierenden Diskursstil wie bei Typ I und Typ II, was prinzipiell einer demokratisch erwünschten Kritik- und Kontrollfunktion entspricht. Viertens - und nicht minder relevant - liefert die typologische Einordnung wesentliche Anhaltspunkte für weitere empirische Forschungen bezüglich alternativer Nachrichtenmedien, zumindest im deutschsprachigen Raum. Gesellschaftliche Implikationen, Publika von alternativen Nachrichtenmedien oder beispielsweise deren Inhalte können nur umfänglich analysiert und kontextualisiert werden, wenn Typenunterschiede berücksichtigt werden. Aus diesem Grund wurde dieser qualitative, explorative Forschungsschritt nach der induktiven Erhebung von potentiellen alternativen Nachrichtenmedien vor weiteren empirischen Analysen vorgenommen. Bereits während der Erhebungsphase wurde dabei deutlich, dass sich alternative News-

132 Basierend auf dem phänomenologischen Ansatz wurde nicht untersucht, ob einschlägige Alternativmedien tatsächlich desinformative Beiträge verbreiten. Vielmehr äusserte sich die Verwendung des «Fake-News»-Begriffes als Kampfbegriff gegenüber dem Mainstream. 
sites untereinander häufig verlinken, sich also gegenseitig referenzieren. Auch deshalb verstärkte sich das Forschungsinteresse hingehend einer Analyse der Netzwerke (oder: Relationen) alternativer Nachrichtenmedien. Da öffentliche Kommunikation auch Publika impliziert, liegt es nahe, als empirischen Wirklichkeitsausschnitt dafür Social-Media-Plattformen heranzuziehen, die Aufschluss über die Zielgruppen der Nachrichtenmedien, im Sinne von Abonnent_innen oder Follower_innen, geben. Darüber hinaus erscheint aufgrund der theoretischen Annahme einer digitalen Transformation der Öffentlichkeit, die vor allem von der Etablierung von Social-Media-Plattformen geprägt ist, die Analyse von Plattformstrukturen vielversprechender als eine weitere Analyse der One-Way-Kommunikation über die Websites. Wie bereits erwähnt, fiel die Wahl für diese Studie auf die Plattform Twitter, die sich nicht nur theoretisch für die Analyse der Relationen zwischen Nachrichtenmedien und weiteren Akteur_innen eignet, da gerade auf dieser Plattform ein Austausch von journalistischen, politischen wie auch Akteur_innen aus der Zivilgesellschaft antizipiert wird, sondern auch aufgrund forschungspraktischer Gründe. Twitter ermöglicht aus rein technischer Sicht eine detaillierte Analyse der Kommunikation von alternativen Nachrichtenmedien, die - wie in Kapitel VII.I beschrieben - auch auf Twitter aktiv sind und deren Beiträge durch Twitter-Nutzer_innen noch weiter verbreitet werden können. Die folgenden Kapitel VII.3 und VII.4 widmen sich den Forschungsfragen nach den Netzwerken bzw. Relationen alternativer Nachrichtenmedien untereinander und weiteren Akteur_innen auf Twitter.

\section{VII.3 FF3: Twitter-Netzwerke alternativer Nachrichtenmedien}

Nachdem im vorangegangenen Kapitel eine Definition alternativer Nachrichtenmedien und eine typologische Unterscheidung basierend auf dem Selbstverständnis der analysierten Medien erfolgten, stellt sich nun eine weitere zentrale Frage der vorliegenden Arbeit:

FF3: Wie sind alternative Nachrichtenmedien untereinander wie auch mit professionellen Nachrichtenmedien und weiteren Akteur_innen des öffentlichen Lebens auf der Digitalplattform Twitter vernetzt?

Die Frage nach der Vernetzung alternativer Nachrichtenmedien ergibt sich aus mehreren bisherigen theoretischen wie auch empirischen Befunden. Der digitale Strukturwandel der Öffentlichkeit ermöglicht demnach nicht nur neuen Kommunikator_innen, Öffentlichkeit herzustellen, sondern gerade die Plattformlogiken (oder «Social Media Logics»), vgl. hierzu van Dijck \& Poell (2013] evozieren eine Vernetzung unterschiedlicher Akteur_innen, die durch ebendiese Relatio- 